Article

\title{
Innovative Mini Ultralight Radioprobes to Track Lagrangian Turbulence Fluctuations within Warm Clouds: Electronic Design
}

\author{
Miryam E. Paredes Quintanilla ${ }^{1, *(\mathbb{D},}$, Shahbozbek Abdunabiev ${ }^{1}$, Marco Allegretti ${ }^{1}$, Andrea Merlone ${ }^{2}$ (D), \\ Chiara Musacchio $^{2} \mathbb{D}$, Eros G. A. Pasero ${ }^{1}$, Daniela Tordella ${ }^{3}\left(\mathbb{D}\right.$ and Flavio Canavero $^{1}(\mathbb{D}$ \\ 1 Politecnico di Torino, Department of Electronics and Telecommunications (DET), Corso Duca Degli Abruzzi 24, \\ 10129 Torino, Italy; shahbozbek.abdunabiev@polito.it (S.A.); marco.allegretti@polito.it (M.A.); \\ d001562@polito.it (E.G.A.P.); flavio.canavero@polito.it (F.C.) \\ 2 Istituto Nazionale di Ricerca Metrologica, Str. Delle Cacce, 91, 10135 Torino, Italy; a.merlone@inrim.it (A.M.); \\ c.musacchio@inrim.it (C.M.) \\ 3 Politecnico di Torino, Department of Applied Science and Technology (DISAT), Corso Duca Degli Abruzzi 24, \\ 10129 Torino, Italy; daniela.tordella@polito.it \\ * Correspondence: miryam.paredes@polito.it
}

check for updates

Citation: Paredes Quintanilla, M.E.; Abdunabiev, S.; Allegretti, M.; Merlone, A.; Musacchio, C.; Pasero, E.G.A.; Tordella, D.; Canavero, F. Innovative Mini Ultralight Radioprobes to Track Lagrangian Turbulence Fluctuations within Warm Clouds: Electronic Design. Sensors 2021, 21, 1351. https://doi.org/ $10.3390 / \mathrm{s} 21041351$

Academic Editor: Carmine Serio

Received: 11 December 2020

Accepted: 8 February 2021

Published: 14 February 2021

Publisher's Note: MDPI stays neutral with regard to jurisdictional claims in published maps and institutional affiliations.

Copyright: (C) 2021 by the authors. Licensee MDPI, Basel, Switzerland. This article is an open access article distributed under the terms and conditions of the Creative Commons Attribution (CC BY) license (https:// creativecommons.org/licenses/by/ $4.0 /)$

\begin{abstract}
Characterization of dynamics inside clouds remains a challenging task for weather forecasting and climate modeling as cloud properties depend on interdependent natural processes at microand macro-scales. Turbulence plays an important role in particle dynamics inside clouds; however, turbulence mechanisms are not yet fully understood partly due to the difficulty of measuring clouds at the smallest scales. To address these knowledge gaps, an experimental method for measuring the influence of small-scale turbulence in cloud formation in situ and producing an in-field cloud Lagrangian dataset is being developed by means of innovative ultralight radioprobes. This paper presents the electronic system design along with the obtained results from laboratory and field experiments regarding these compact (diameter $\approx 30 \mathrm{~cm}$ ), lightweight $(\approx 20 \mathrm{~g}$ ), and expendable devices designed to passively float and track small-scale turbulence fluctuations inside warm clouds. The fully customized mini-radioprobe board $(5 \mathrm{~cm} \times 5 \mathrm{~cm})$ embeds sensors to measure local fluctuations and transmit data to the ground in near real time. The tests confirm that the newly developed probes perform well, providing accurate information about atmospheric turbulence as referenced in space. The integration of multiple radioprobes allows for a systematic and accurate monitoring of atmospheric turbulence and its impact on cloud formation.
\end{abstract}

Keywords: atmospheric probe; instrumented balloon; research sonde; atmospheric turbulence; warm clouds; Lagrangian measurements; wireless sensor network; LoRa; low-power sensors

\section{Introduction}

Clouds are a natural complex feature of Earth and a key element in climate change and climate sensitivity, since their characteristics directly influence the global radiation budget, the global hydrological cycle (through precipitation), and the atmospheric dynamics [1,2]. Clouds cover approximately two thirds of the globe at any time, and they are the principal source of uncertainty in future climate and weather projections [3-6]. This is because clouds involve processes on a vast range of spatial and temporal scales, ranging from the order of few microns, where droplets nucleate and collide-coalesce, to the thousands of kilometers reachable by the larger storm systems [6]. Clouds represent a substantial challenge for scientific understanding and modeling, since the available methods are not yet able to characterize the entire cloud system and related interactions across scales.

Both the intense turbulence of the airflow hosting the clouds and the less intense turbulence that characterizes the environmental clear air surrounding them $[7,8]$ play an important role in cloud evolution and precipitation. Nonlinear dynamical processes 
of vortex stretching, entrainment, and mixing greatly influence the nucleation of water droplets and associated evaporation-condensation and collision-coalescence [7]. To address these knowledge gaps, different laboratory experiments, field observations, and numerical simulations have been undertaken to understand cloud microphysics and, particularly, the inherent turbulent interactions. Investigation methods include remote sensing by means of radars and lidars $[9,10]$, in situ observations including manned and unmanned airborne platforms (airplanes, helicopters, tethered lifted systems, etc.) [11-13], laboratory experiments in wind tunnels and climate chambers [14-16], and numerical simulation experiments carried out via Navier-Stokes direct numerical simulation of small portion of clouds $[17,18]$.

We present here an in situ method for measuring the influence of small-scale turbulence in cloud formation, which is based on the design and implementation of an innovative ultralight (about $20 \mathrm{~g}$ ) biodegradable and expendable radiosonde here referred to as radioprobe. A radiosonde is a battery-powered instrument carried into the atmosphere usually by a weather balloon with radio transmitting capabilities [19]. The idea was developed during the proposal writing of a European Horizon 2020 Marie Sklodowska Curie project which was approved in 2016 (H2020 MSCA ITN ETN COMPLETE, GA 675675: Innovative Training Network on Cloud-MicroPhysics-Turbulence-Telemetry [6]). The mini radioprobes are used to passively track turbulent fluctuations of air velocity, water vapor, and droplets concentration, temperature and pressure in warm clouds and surrounding ambient air according to the Lagrangian description [20] of turbulent dispersion, as proposed by Richardson in 1926 [21,22].

These compact light-weighted devices with a maximum target weight of $20 \mathrm{~g}$ and diameter of $30 \mathrm{~cm}$ are designed to float at altitudes between 1-2 $\mathrm{km}$ and be alive for approximately $1 \mathrm{~h}$. The radioprobes are capable of passively tracking small-scale turbulence fluctuations inside warm clouds and surrounding air since they can be considered as markers in a Lagrangian description of the airflow. In order to enable them to float, the radioprobe electronics are housed inside $30 \mathrm{~cm}$-diameter balloons made of biodegradable materials that are filled with an adequate mixture of helium gas and ambient air to reach a buoyancy force equal to the system weight. Considering that the floating devices will not be recovered once they have finished their mission, the design accounts for the use of environmental-friendly materials to minimize any possible negative impact on the environment (i.e., green). To this end, the external balloons are made of biodegradable materials tailored to provide hydrophobicity and flexibility properties [23]. In the context of research balloons, these innovative devices can be catalogued as mini ultralight instrumented weather balloons. However, they are different from other instrumented devices developed for atmospheric sounding, like the NCAR-NOAA Global Hawk tethered dropsonde (weight $167 \mathrm{~g}$, length $30.5 \mathrm{~cm}$, diameter $4.6 \mathrm{~cm}$; square-cone parachute $20 \mathrm{~cm}$ on a side) used for vertical atmospheric profiling measurements (no Lagrangian trajectories) and launched by an unmanned aircraft from the National Aeronautics and Space Administration (NASA) [24], or the NOAA ground-launched smart balloon (diameter of $335 \mathrm{~cm}$ ) housing the sensors inside the enclosure and used for Lagrangian experimental hurricane research [25]. Additional devices are the short-range ground-launched weather balloon from NOAA carrying a tethered radiosonde (balloon diameter about $152 \mathrm{~cm}$ ) [26], and the air-released balloon-tethered microsonde (total weight $65.6 \mathrm{~g}$ ) for supercell thunderstorm studies [27].

The Lagrangian balloons described in this article behave as instrumented particles embedding a set of compact size sensors for the measurement of local fluctuations of temperature, pressure, humidity, acceleration, and trajectory. They can be released into the atmosphere from unmanned aerial vehicles or small airplanes. During the flight, the smart radioprobes acquire, preprocess, store, arrange, and transmit in real time the obtained data to different ground stations located on earth through a dedicated long-range power-saving wireless radio transmission link [28]. 
This paper focuses entirely on the electronics design of the new radioprobe and is organized as follows: Section 2 describes the radioprobe environment and addresses the design requirements. Section 3 describes the system architecture and the design methodology. Section 4 reports on the performance evaluation. Section 5 presents the conclusions and future work.

\section{Understanding the Sensor Environment and Design Requirements}

The miniprobes are conceived to work at the submeter level and measure smallscale turbulence fluctuations inside warm clouds. To this end, they must have unique characteristics that allow them to behave as instrumented particles and track Lagrangian trajectories once being released into the atmosphere. This specific kind of radioprobe must be as small as possible to have a minimal inertia and a minimal size (diameter) compared to the expected trajectory length. Also, it must be able to passively follow cloud fluctuations. To float on an isopycnic surface, the density of the radioprobe must correspond to the density of air at the target flight altitude (between 1 and $2 \mathrm{~km}$ ). To this end, the weight and volume of the radioprobe's balloon must remain relatively unaltered for the duration of the flight as presented in an initial study of the balloon materials in [23]. On that basis, the size required for the instrumented balloon to float was determined by the Archimedes' principle for buoyancy. The spherical balloon size must be about $30 \mathrm{~cm}$ in diameter. We expect our mini green radioprobes to maintain a steady trajectory, remaining within a few hundred meters vertically and a few kilometers horizontally of its initial release point. This is a physical space that includes both the cloud, or part of it, and a part of the surrounding undersaturated air.

As regards the classification of the geophysical motion scales, the turbulence that characterizes the cloud systems aimed to study with these new radioprobes is the so-called small geophysical scale. This scale concerns motions of length orders lower than or equal to $10 \mathrm{~km}$. It is three-dimensional and not necessarily includes large-scale coherent vortices as those which are typical of the coherent vortices in rotating barotropic flows $[29,30]$. The clouds we are interested in are thermal-convective clouds. They develop by convection in the Earth's atmosphere because of the intense solar-radiation heating of the ground and in the presence of colder air masses at high altitude. These clouds are mainly typical of the spring and summer seasons, and have a local range of action, especially in the mountainous/hilly inland areas as well as in the great plains. The turbulence that characterizes them is devoid of shear and very frayed. It is particularly anisotropic and intermittent in the vicinity of the areas where the interaction between the cloud and the subsaturated ambient air takes place. At present, as this type of radioprobes is brand new, there is no information on the drift they could undergo from the actual Lagrangian trajectories followed by the airflow particles and water droplets, which are housed inside the clouds. We expect that future field experiments will provide new results regarding this subject. The mini green expendable radioprobes are intended to measure eddies larger than $0.5-1 \mathrm{~m}$, with a maximum frequency of around $0.5-1 \mathrm{~Hz}$ and a kinetic energy per unit of mass in between $0.001-0.01(\mathrm{~m} / \mathrm{s})^{2}$. The higher limit is around a few kilometers, which corresponds to frequencies as low as $10^{-4} \mathrm{~Hz}$.

Since a large number of radioprobes is required for the scope, they should have a low cost. Although current radioprobe manufacturing and launch procedures (either from the ground or aircraft) are relatively inexpensive [31], the miniaturization of these innovative devices, together with the non-necessity of a mother aircraft, expensive ground-launch station, or complex logistics, will further reduce costs associated with their production and release.

Each device must include sensors to measure velocity, acceleration, vorticity, pressure, temperature, and humidity fluctuations inside warm clouds. According to the environmental conditions that can be found inside real clouds, the operational requirements for the radioprobe sensors can be summarized as follows: external temperature, ranging from 0 to $+30{ }^{\circ} \mathrm{C}$; external relative humidity $(\mathrm{RH})$ : ranging from 0 to $100 \% \mathrm{RH}$; external pressure: 
ranging from 400 to 1100 mbar; trajectory: +/ -100 mm accuracy; and air-flow fluctuation: up to $5-6 \mathrm{~m} / \mathrm{s}$ inside a cloud.

The data collected during the flight must be sent wirelessly to a data-acquiring system on earth whilst the device is alive. For this purpose, a transmission technology able to reach relatively long distances without consuming much power is required.

\section{Radioprobe System Architecture and Design Methodology}

The working principle of the entire system is shown in Figure 1. This wireless sensor network (WSN) is structured in three main parts: (1) the bioballoon-wrapped radioprobe, which includes the solid-state sensors to measure the physical quantities of interest and which transmit the collected and preprocessed data to the ground; (2) the base stations, which receive, store, and pass this information to the processing machine; and (3) the processing machine, which is used for database management, filtering, and visualization.

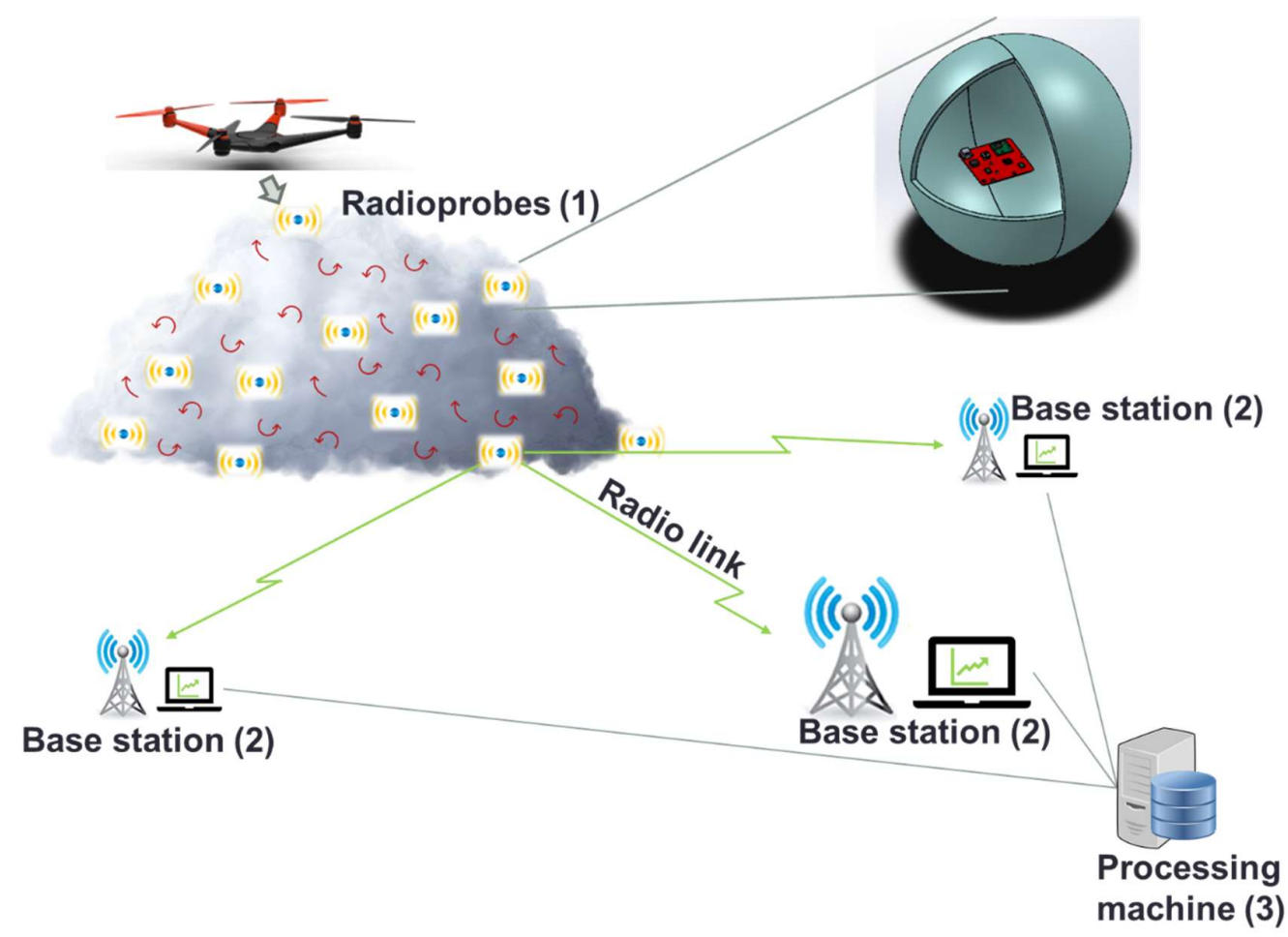

Figure 1. Working principle and radioprobe system architecture.

The block diagram of the radioprobe is illustrated in Figure 2, where the system is represented by its several functional units: (1) a data-processing and control unit, (2) a radiocommunication system, (3) a temperature, pressure, and humidity sensor stage, (4) a positioning and tracking sensor stage, and (5) a power supply unit.

The printed circuit board (PCB) realization of the radioprobe is displayed in Figure 3. All the electronics are assembled on both sides of a two-layer FR4 substrate with surfacemount technology (SMD) components. It is a $50 \mathrm{~mm} \times 50 \mathrm{~mm}$ rectangular structure with a thickness of $0.8 \mathrm{~mm}$ and weight of $7 \mathrm{~g}$ (without the battery). The following subsections provide further details of each functional block of the miniprobe and the ground station. 


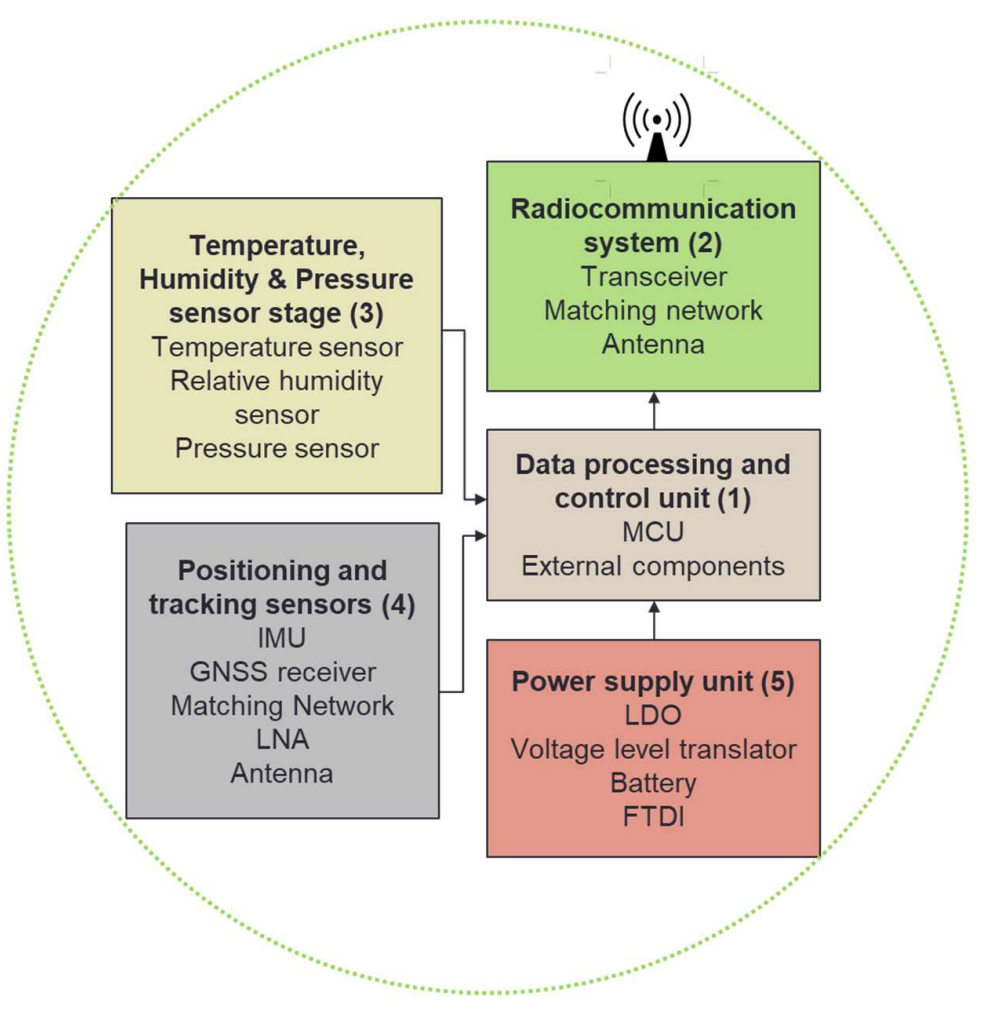

Figure 2. Block diagram of the mini radioprobe.

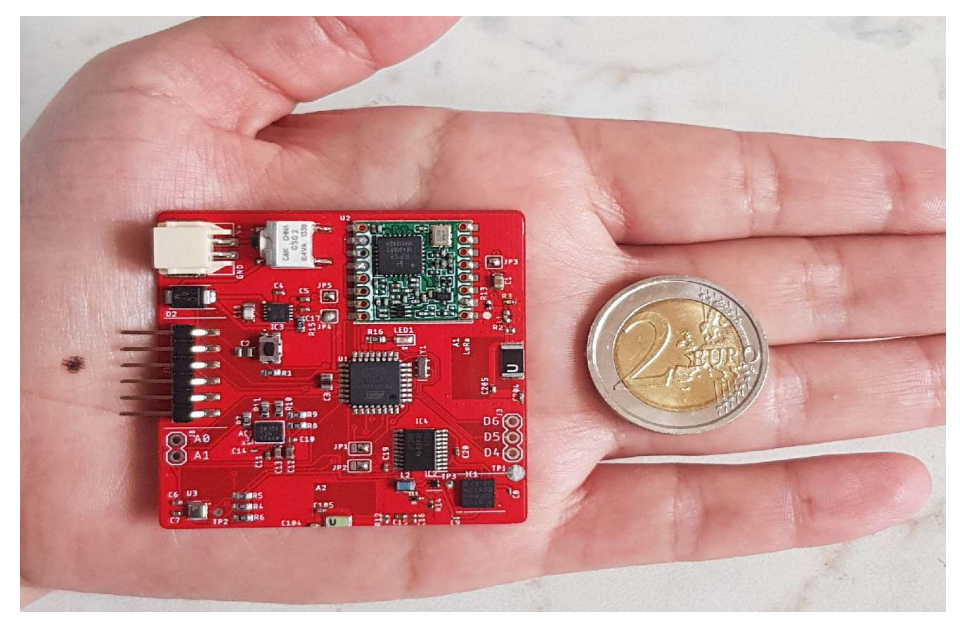

Figure 3. Top view of the PCB implementation of the radioprobe. Size, $50 \mathrm{~mm} \times 50 \mathrm{~mm}$. Weight, $7 \mathrm{~g}$.

\subsection{Data-Processing and Control Unit}

The data-processing and control unit block is the computational module of the radioprobe. It allows controlling and executing different subsystem processes in an automated way inside the device. In this unit, the data delivered by the sensors are interpreted, processed, saved, and sent through the transmission module to the ground stations. For this purpose, the onboard low-power complementary metal-oxide semiconductor (CMOS) 8-bit microcontroller ATmega328 from Microchip [32] has been selected as the central processing unit. It has 32 pins in a thin quad flat pack (TQFP) package with compact dimensions of $9 \mathrm{~mm} \times 9 \mathrm{~mm} \times 1 \mathrm{~mm}$ and a weight of $70 \mathrm{mg}$. The microcontroller requires a supply voltage in the range from 1.8 to $5.5 \mathrm{~V}$ and operates within temperature ranges from -40 to $+85^{\circ} \mathrm{C}$. It requires low current consumption, i.e., $0.2 \mathrm{~mA}$ in active mode, $0.1 \mu \mathrm{A}$ in power-down mode, and $0.75 \mu \mathrm{A}$ in power-save mode @ $1 \mathrm{MHz}, 1.8 \mathrm{~V}, 25^{\circ} \mathrm{C}$. 


\subsection{Radio Communication System}

The radio communication system of the miniprobes enables the one-way wireless communication with ground stations using radiofrequency signals. Due to the required criteria of the artificial floating probes, LoRa communication technology has been adopted. LoRa is a chirp spread spectrum (CSS) modulation technique, which encodes information in linearly increasing chirps [33,34]. LoRa was originally developed for the Internet of things (IoT), and since its release, it underwent enormous growth, being adapted for a wide range of applications [35]. Although LoRa is being used as part of the open-source LORAWAN specification, in this work, it is used to create an ad hoc private network and adapt the technology to the working scenario. To this end, the commercial off-the-shelf LoRa-based transceiver module RFM95 from HopeRF was used [36]. This transceiver and therefore the communication technology were previously tested by the authors under different scenarios [28,37-40]. It is a module featuring long-range spread-spectrum communication links and high immunity to interference whilst optimizing the power use. This module allows power-transmission ranges within $5 \mathrm{dBm}(3.16 \mathrm{~mW})$ to $20 \mathrm{dBm}(100 \mathrm{~mW})$, although according to the regulations released by the European Telecommunications Standards Institute (ETSI), the maximum power allowed in the European area is $14 \mathrm{dBm}(25.12 \mathrm{~mW})$ [41]. It requires a supply voltage in the range from 1.8 to $3.7 \mathrm{~V}$ and operates within temperature ranges from -20 to $+70{ }^{\circ} \mathrm{C}$. The typical current consumption required by the transceiver are $0.2 \mu \mathrm{A}$ in sleep mode, $1.5 \mu \mathrm{A}$ in idle mode, $20 \mathrm{~mA}$ in transmit mode $@+7 \mathrm{dBm}$ output power (OP), 29 mA in transmit mode @ +13 dBm OP, and 120 mA in transmit mode @ $+20 \mathrm{dBm}$ OP.

\subsection{Antennas}

Each tiny radioprobe includes two RF stages, one for the transmission of the in-flight collected data to ground stations and one for the reception of positioning and timing data from satellites. The antennas used for the two stages are ceramic quarter-wave chip antennas embedded in the system, one working in the LoRa sub-1GHz frequency band and the other in the L1 frequency band, respectively. Both antennas used for the transmission and reception of the radioprobe data are linearly polarized and have small dimensions, i.e., $5 \mathrm{~mm} \times 3 \mathrm{~mm} \times 0.5 \mathrm{~mm}$ and $3.2 \mathrm{~mm} \times 1.6 \mathrm{~mm} \times 0.5 \mathrm{~mm}$, respectively. They were mounted at the center of two different edges of the PCB top side and, since the chip itself is half of the antenna design, the bottom side of the PCB includes the ground-plane layer to complete the antenna system. In addition, in order to minimize electric fields generated at the edge of the PCB and reduce crosstalk, via shielding was incorporated alongside the path of the RF signals and the ground clearance areas [42]. Moreover, with the purpose of ensuring the best possible RF performance, impedance matching practices were performed to ensure that most of the power was delivered between the transceivers and the antennas during the transmission and reception processes. The matching network extensions used for the antennas' tuning are L-section type, which uses reactive elements to match the load impedance to the transmission line.

\subsection{Temperature, Barometric Pressure, and Relative-Humidity Measurement}

After an extensive analysis of possible options and based on the physical constraints of the design, the combined module BME280 [43], which is a humidity sensor measuring ambient temperature, relative humidity, and barometric pressure, was selected as the most suitable choice for the miniprobes. This all-in-one option consumes very little current (in the order of the $\mu \mathrm{A}$ ), which makes it ideal for battery-powered purposes as in the present case. The device comes in a land grid array (LGA) package of dimensions $2.5 \mathrm{~mm} \times 2.5 \mathrm{~mm} \times 0.93 \mathrm{~mm}$ and requires a supply voltage in the range from 1.2 to $3.6 \mathrm{~V}$. The operating ranges of the device are 0 to $100 \% \mathrm{RH}$ for relative humidity, 300 to $1100 \mathrm{hPa}$ for pressure, and -40 to $+85{ }^{\circ} \mathrm{C}$ for temperature. In terms of overall performance, this device provides a maximum uncertainty of $\pm 3 \% \mathrm{RH}$ and a resolution of $0.008 \% \mathrm{RH}$ for relative humidity, a maximum uncertainty of $\pm 1 \mathrm{hPa}$, and a resolution of $0.18 \mathrm{~Pa}$ for pressure, 
and a maximum uncertainty of $\pm 1{ }^{\circ} \mathrm{C}$ and an output resolution of $0.01{ }^{\circ} \mathrm{C}$ for temperature measurements. The response time of the BME280 depends on the oversampling mode, selected filter, and the data rate used. The oversampling modes available are 1, 2, 4, 8, and 16. The temperature, pressure, and relative-humidity measurements are extracted through reading commands implemented in the microcontroller. In the final radioprobe version, these sensors will be placed outside the balloon to be in direct contact with the atmosphere under study.

\subsection{Positioning and Tracking Measurement}

In the Lagrangian reference system, the fluid-flow properties are determined by tracking the motion and properties of the individual fluid particles as they move in time [44]. For the radioprobe, the physical quantities already explained in the previous subsection will be measured along the trajectory of the fluid particle as time passes. In this way, if many fluid particles (radioprobes) are tracked at the same time, the fluid properties for the whole domain can be obtained. The positioning and tracking electronic block allow one to collect useful data to determine the trajectory and position followed by the radioprobe during its flight. The positioning and motion tracking is executed as a postprocessing task at the ground level and is obtained by sensor-fusion algorithms based on Kalman and orientation filters. The orientation filter is used to fuse data coming from an inertial measurement unit IMU, and the Kalman filter exploits the output of the orientation filter and fuses it with the data coming from a Global Navigation Satellite System (GNSS) receiver.

The IMU used for this block is the nine-axis inertial module device LSM9DS1 [45] that combines a three-axis digital linear acceleration sensor, a three-axis digital angular rate sensor, and a three-axis digital magnetic sensor, all in a single package. It comes in a compact LGA package of dimensions $3.5 \mathrm{~mm} \times 3 \mathrm{~mm} \times 1.0 \mathrm{~mm}$, requires a supply voltage in the range from 1.9 to $3.6 \mathrm{~V}$, and operates within temperature ranges from -40 to $+85^{\circ} \mathrm{C}$. The device has a linear acceleration measurement range of $\pm 2, \pm 4, \pm 8$, and $\pm 16 \mathrm{~g}$; a magnetic field full scale of $\pm 4, \pm 8, \pm 12$, and \pm 16 gauss; and an angular rate full scale of $\pm 245, \pm 500$, and \pm 2000 dps. The output data rate configuration modes available for the IMU sensors are 10-952 Hz for the accelerometer, 14.9-952 Hz for the gyroscope, and $0.625-80 \mathrm{~Hz}$ for the magnetometer. The typical current consumption required by the IMU when operating in normal mode is $600 \mu \mathrm{A}$ for the accelerometer and magnetic sensors and $4 \mathrm{~mA}$ for the gyroscope $@ 2.2 \mathrm{~V}, \mathrm{~T}=25^{\circ} \mathrm{C}$. The main function of the IMU unit is to provide force, angular rate, and orientation information of the radioprobe flight.

The GNSS receiver unit used in this block is a professional ultrasmall, super-lowpower system-in-package (SiP) ZOE-M8B [46] module that offers a super-efficient (Super-E) mode option for improving the power consumption. It comes in an advanced soldered land grid array (S-LGA) package of dimensions $4.5 \mathrm{~mm} \times 4.5 \mathrm{~mm} \times 1.0 \mathrm{~mm}$, requires a supply voltage in the range from 1.71 to $1.89 \mathrm{~V}$, operates within temperature ranges from -40 to $+85^{\circ} \mathrm{C}$, and draws low current, i.e., $34.5 \mathrm{~mA}$ for acquisition, $32.5 \mathrm{~mA}$ for tracking (continuous mode), $7.3 \mathrm{~mA}$ (Super-E mode), and $6.3 \mathrm{~mA}$ (Super-E mode power save) @ $1.8 \mathrm{~V}, 25^{\circ} \mathrm{C}$. For GPS and Global Navigation Satellite System (GLONASS), the GNSS receiver provides a horizontal position accuracy of $3.5 \mathrm{~m}$ (Super E-mode), $2.5 \mathrm{~m}$ (continuous mode), and $4.0 \mathrm{~m}$ (Super E-mode power save), with a maximum navigation update rate of $10 \mathrm{~Hz}$ for continuous mode and $4 \mathrm{~Hz}$ for Super-E mode. This receiver module can measure dynamics up to $4 \mathrm{~g}$ at altitudes up to $50 \mathrm{~km}$ and velocities up to $500 \mathrm{~m} / \mathrm{s}$. The GNSS is connected to the microcontroller through a bidirectional voltage-level translator, which serves as an interface for the different voltage requirements. The GNSS signal input is attached to an additional external low-noise amplifier (LNA) for best performance in terms of noise figure and robustness against jamming, RF power and electrostatic discharge (ESD). The main function of the GNSS unit is to provide periodic reference position information of the radioprobe flight for removing drifts in the IMU output. Since the GNSS receiver consumes relatively more power than the other sensors, the Super E-mode, combined with periodic off and on periods of the GNSS module, is used to save power. 


\subsection{Power Supply Unit}

Power consumption is a critical key of the radioprobe design since it is closely related to the total weight of the device. The power supply block provides the electric power to the system and incorporates two different options to energize the circuit. The first option consists of a single non-rechargeable battery used to provide enough power to the electronic circuit while keeping the whole system light and autonomous during the flight. To this purpose, a single $4.0 \mathrm{~V}$ lithium metal oxide (LMO) battery with nominal capacity of $125 \mathrm{mAh}$ and pulse current capacity of $3.75 \mathrm{~A}$ is used. The cell's weight is $9 \mathrm{~g}$ with a volume of $3.2 \mathrm{~cm}^{3}$ and a wide temperature operating range of -55 to $+85^{\circ} \mathrm{C}$. This battery complies with Underwriters Laboratories, Inc. (UL) safety standards. It is made of nontoxic and nonpressurized solvents and includes less reactive materials than standard lithium cells. The second option includes an FTDI USB-to-serial connection used mostly for code uploading and management purposes. To provide the required supply voltages ( 3.3 and $1.8 \mathrm{~V}$ ) to the different components, the circuit incorporates the dual low-dropout (LDO) voltage regulator LP3996SD [47], which can source 150 and $300 \mathrm{~mA}$ at an ultralow quiescent current of $35 \mu \mathrm{A}$.

\section{Experimental Results and Discussion}

This section reports on the outcomes of the different experiments performed to validate the radioprobe system. The performance of the system was assessed based on communication reliability, sensor reliability, and power consumption.

\subsection{Antenna Matching and Data Transmission Ranges}

To improve the radioprobe-antenna system performance, the antennas' characterization was done by measuring their complex impedance values and adjusting the matching network components to obtain an acceptable S11. To this end, the portable USB vector network analyzer (VNA) Keysight P9371A, was employed. Since the antenna impedances were not matched to $50 \mathrm{ohms}$ as expected, the L-type matching components were calculated based on the normalized load impedance and then soldered on the PCB to improve the quality of the match. Moreover, the resonance frequency of the antennas was shifted to the desired ones (around 868 and $1575 \mathrm{MHz}$ ). The results of the matching and frequency-tuning procedures for both the transmission and reception RF stages are shown in Table 1.

Table 1. Results of the matching and frequency-tuning procedures.

\begin{tabular}{ccc}
\hline Frequency $[\mathrm{MHz}]$ & ${\text { Initial } \mathbf{S}_{\mathbf{1 1}}[\mathbf{d B}]}$ & Final $_{\mathbf{1}_{\mathbf{1 1}}}[\mathbf{d B}]$ \\
\hline 865.2 & -0.59 & -23.99 \\
868.0 & -0.56 & -21.09 \\
1575.0 & -1.22 & -23.09 \\
1602.0 & -1.22 & -17.34 \\
\hline
\end{tabular}

As a result of this process, the performance of both antenna systems was considerably improved. The initial reflection coefficients of the system were enhanced by approximately 40 times for the transmission RF stage and 19 times for the receiving RF stage, thus, ensuring in this way the maximum power transfer in the RF units.

In addition, with the goal of testing the communication system of the radioprobe, some sets of measurements using different network configurations were carried out. The initial field measurement (Setup 1, Figure 4) included propagation measurements using a pointto-point static network configuration in an urban environment to identify the transmission ranges of the system in harsh propagation conditions. This test was carried out in the city of Turin, Italy, specifically within our university and its surroundings. The network setup included a radioprobe (transmitter) creating and sending a unique sensor identification (ID) together with a counter, and a ground station (receiver) receiving and storing the messages. The aim of the counter was to identify the losses of packets having a known progressive number included in the data frame. The transmitter was located at eight different positions 
from P1 to P8, while the receiver was located at a fixed position Rx. Also, at the receiver side, the spectrum analyzer (SA) model R\&S ZVL was placed to measure the power of the signal spectrum; however, for most of the points, the noise floor of the instrument was higher than the incoming signal; thus, the measurement of the power spectrum was not possible. This behavior emphasizes the robustness of LoRa technology and the opportunity to establish communication links in challenging environments. The receiver module was programmed in order to provide useful information about the signal quality, that is, signal-to-noise ratio (SNR) and received-signal-strength indicator (RSSI) of the packets. The receiver was placed at an approximated height of $17 \mathrm{~m}$ and the transmitter at a height of $1 \mathrm{~m}$ above the street level. The tests were made using a programmed output power of $10 \mathrm{dBm}$, central frequency $865.2 \mathrm{MHz}$, spreading factor of 10 , and a bandwidth of $125 \mathrm{kHz}$. The set of analyzed data consisted of blocks of 200 packets for each transmitter position. The fixed location of the ground station and the different positions of the transmitter (radioprobe) are shown in Figure 4. The obtained results of the measurements are reported in Table 2.

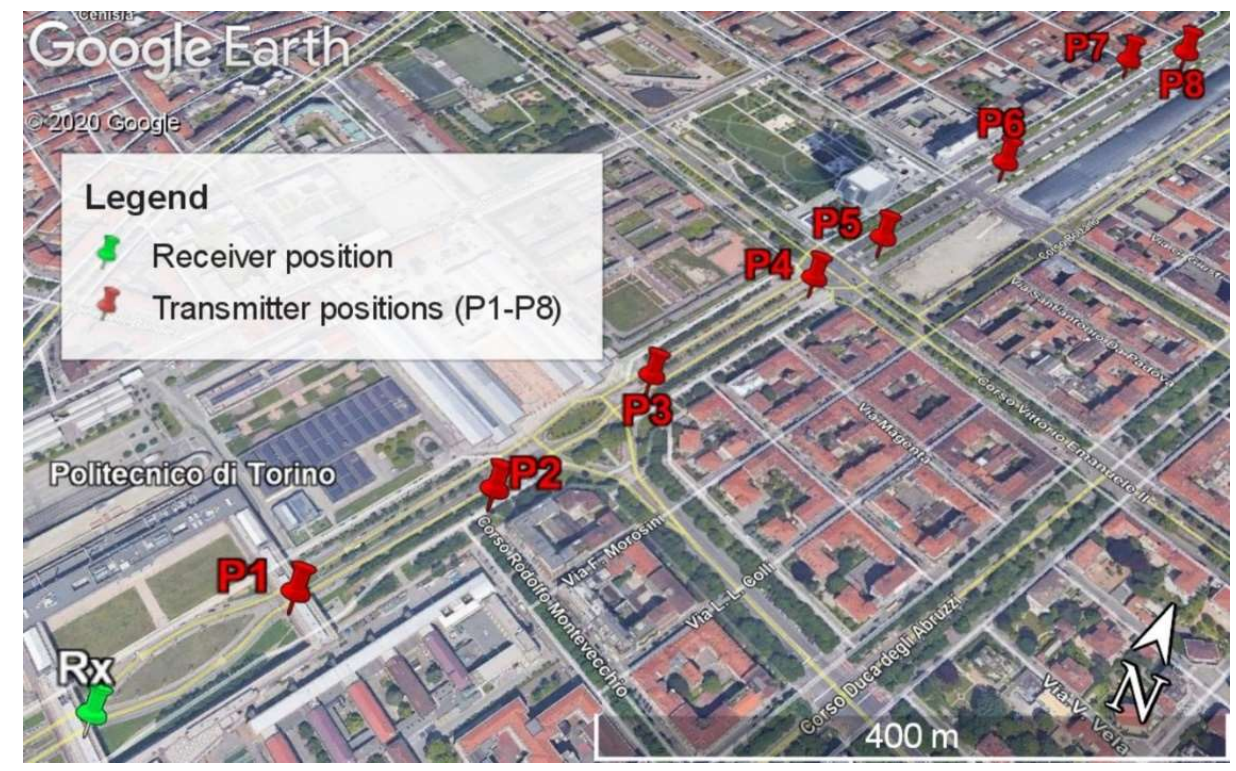

Figure 4. System Setup 1 used to determine the transmission ranges reached by the radioprobe system in an urban environment displayed on a map. Transmitters (P1 to P8) and receiver (Rx) position with relative distance indications. Google Earth view.

Table 2. Results of the point-to-point measurements in urban environment (Setup 1).

\begin{tabular}{ccccc}
\hline Tx Position & Distance $[\mathbf{m}]$ & SNR Mean [dB] & $\begin{array}{c}\text { RSSI Mean } \\
{[\mathbf{d B m}]}\end{array}$ & $\begin{array}{c}\text { Received } \\
\text { Packets [\%] }\end{array}$ \\
\hline P1 & 138 & 7 & -95 & 100.0 \\
P2 & 280 & 2 & -113 & 99.5 \\
P3 & 455 & -7 & -123 & 99.5 \\
P4 & 648 & -9 & -124 & 77.8 \\
P5 & 737 & -2 & -120 & 99.5 \\
P6 & 905 & -9 & -125 & 96.0 \\
P7 & 1173 & -13 & -122 & 95.5 \\
P8 & 1232 & -12 & -124 & 52.0 \\
\hline
\end{tabular}

As a result of these propagation measurements, different transmission links were tested to understand the transmission ranges that can be reached by the system, of course, in a more difficult environment where partial or total obstruction of the Fresnel zone is present. The closest eight different transmitter positions (P1 to P8) were selected since the percentage of received packets was greater than $50 \%$. The maximum propagation distance 
tested was $1232 \mathrm{~m}$ of distance between the transmitter and the receiver. In most positions, the communication link was affected by direct obstacles and reflections from diverse sources, which is a common propagation issue in built-up areas. For all the measurements, the SNR ranged from $+7 \mathrm{~dB}$ at the nearest distances to $-13 \mathrm{~dB}$ at the longest ones. The negative SNR values obtained is an inherent LoRa characteristic, which indicates the ability of this technology to receive signal power below the receiver noise floor [48]. As expected, the RSSI of the packets decreased with distance and non-line-of-sight (NLOS) between the transmitter and the receiver; however, for most of the cases, the percentage of received packets was higher than 95\%. These measurements provided a good reference of possible transmission ranges that can be achieved by the radioprobes when floating into the unobstructed free atmosphere environment.

A second field measurement included propagation measurements using a point-topoint dynamic network configuration in an open-area environment (Setup 2, Figure 5). Unlike the previous experiment, the mini radioprobe transmitting the information was attached to a reference radiosonde, which was part of an automatic atmospheric sounding system to simulate similar conditions in which the radioprobes will be released. This experiment was carried out at the Cuneo Levaldigi meteorological station (id LIMZ) of the Regional Agency for the Protection of the Environment (ARPA) of Piedmont, Italy, where an atmospheric balloon is launched into the atmosphere twice a day. The sounding system consisted of a large helium-filled balloon of about $1.5 \mathrm{~m}$ in diameter, tethered by a polypropylene string a Vaisala RS41 radiosonde and able to provide temperature, humidity, wind, height, and pressure information through a telemetry link to ground stations.

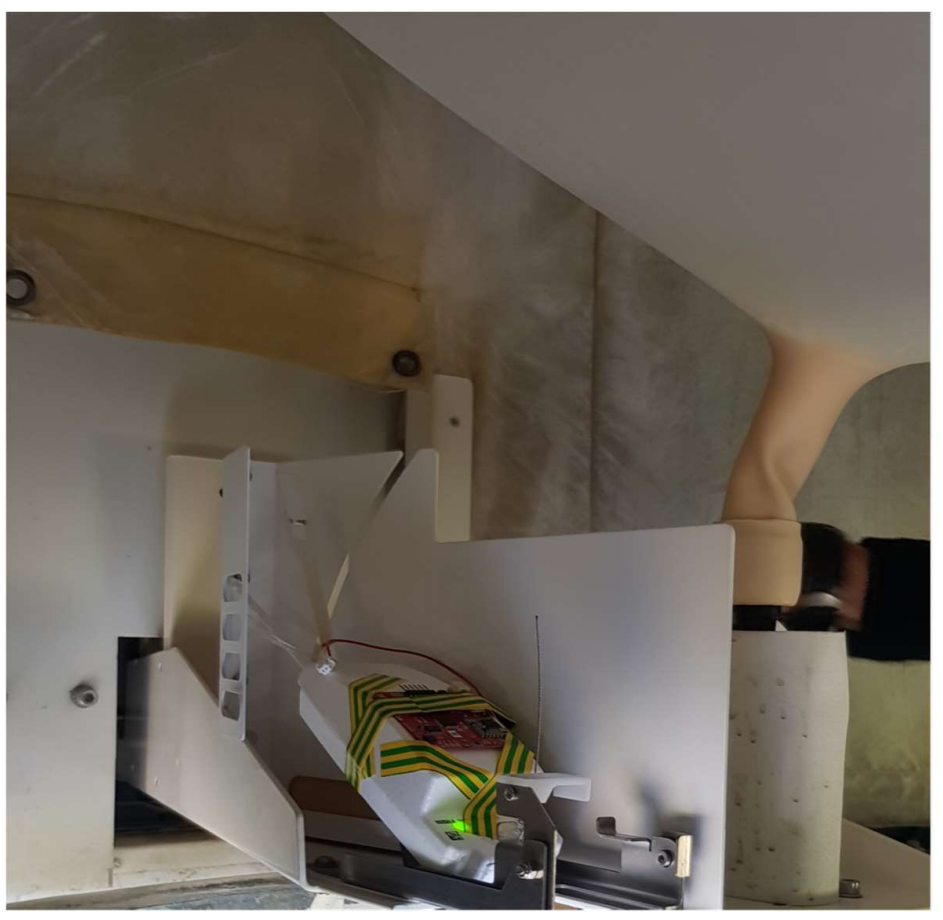

Figure 5. System setup 2 used to determine the transmission ranges reached by the radioprobe system in an open-area environment. Tiny radioprobe attached to the reference atmospheric sounding system.

The network setup for this measurement included a fully operational mini radioprobe gathering, processing, packing, and transmitting the information from the different sensors, and a ground station receiving, storing, and postprocessing the received messages. The tiny radioprobe was attached to the front side of the reference radiosonde's cover and activated just before the launch to save energy for the flight. The radioprobe's transceiver was programmed to provide an output power of $14 \mathrm{dBm}$ at a central frequency of $865.2 \mathrm{MHz}$, spreading factor of 10 , and bandwidth of $125 \mathrm{kHz}$. The receiver was placed close to the 
ground at an approximated height of $1 \mathrm{~m}$. Because this set of measurements was carried out in a nonobstructed open environment, the transmitter was in LOS with the receiver at all positions. The system setup and trajectory followed by the systems with respect to the ground station are shown in Figures 5 and 6, respectively.

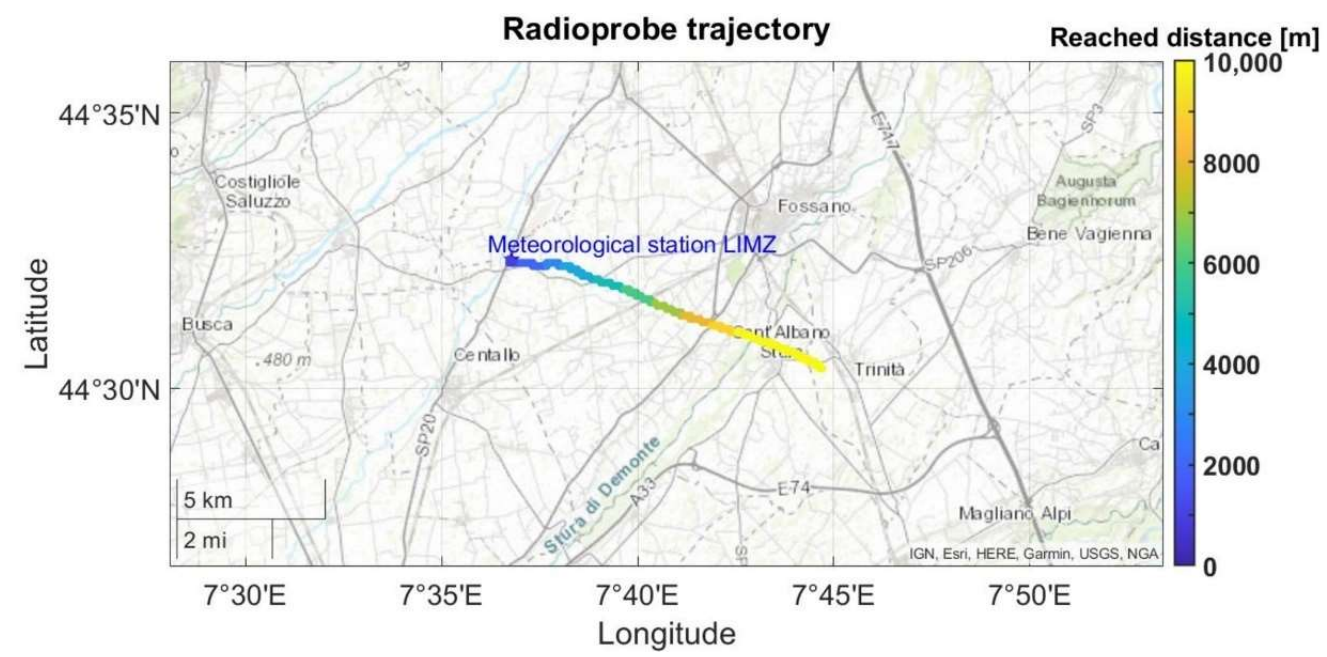

Figure 6. Trajectory of the fully operational radioprobe attached to the reference atmospheric sounding system, displayed on a map. The color bar indicates the separation distance reached by the system with respect to the ground station.

As a result of these propagation measurements, the maximum transmission range reached by the radioprobe system in an open environment was determined. Although the reference atmospheric sounding system was intended for vertical atmospheric profiling measurements of the troposphere and low stratosphere and not for warm-cloud environments with heights between 1 and $2 \mathrm{~km}$, it provided a good reference to test our system in a dynamic atmosphere environment free of obstacles. A summary of the obtained results of the measurements is reported in Table 3.

Table 3. Results of the point-to-point measurements in open environment (Setup 2).

\begin{tabular}{cccccc}
\hline Distance [m] & $\begin{array}{c}\text { SNR Mean } \\
\text { [dB] }\end{array}$ & $\begin{array}{c}\text { RSSI Mean } \\
\text { [dBm] }\end{array}$ & $\begin{array}{c}\text { Total } \\
\text { Transmitted } \\
\text { Packets }\end{array}$ & $\begin{array}{c}\text { Number of } \\
\text { Received } \\
\text { Packets }\end{array}$ & $\begin{array}{c}\text { Received } \\
\text { Packets [\%] }\end{array}$ \\
\hline Up to 1000 & 5 & -95 & 40 & 37 & 92.5 \\
Up to 2000 & 4 & -99 & 103 & 98 & 95.2 \\
Up to 3000 & 2 & -102 & 156 & 146 & 93.6 \\
Up to 4000 & 2 & -103 & 210 & 196 & 93.3 \\
Up to 5000 & 1 & -104 & 243 & 226 & 93.0 \\
Up to 6000 & 1 & -104 & 276 & 240 & 87.0 \\
Up to 7000 & 0 & -105 & 297 & 259 & 87.2 \\
Up to 8000 & 0 & -105 & 322 & 283 & 87.9 \\
Up to 9000 & -1 & -106 & 348 & 294 & 84.5 \\
Up to 10,000 & -1 & -106 & 376 & 296 & 78.7 \\
Up to 11,000 & -1 & -106 & 449 & 297 & 66.2 \\
Up to 14,000 & -1 & -106 & 462 & 298 & 64.5 \\
\hline
\end{tabular}

The reference atmospheric sounding system carrying the attached mini radioprobe reached a maximum height of approximately $32 \mathrm{~km}$ and a horizontal range of approximately $108 \mathrm{~km}$ before the balloon burst. The tiny radioprobe reached a maximum height of approximately $11 \mathrm{~km}$, a horizontal range of $7 \mathrm{~km}$, and a straight distance of $13 \mathrm{~km}$ before losing contact with the ground station. In total, 462 packets were sent from the mini radioprobe during the flying time for a time span of approximately $22 \mathrm{~min}$ after the launch. 
For all the measurements, the SNR ranged from $+5 \mathrm{~dB}$ at the nearest distances to $-1 \mathrm{~dB}$ at the longest ones. As expected, the RSSI of the packets decreased with the increase in distance between the transmitter and the receiver. Although there was an intermittency in the reception of some packets due to the high ascending velocity of the sounding system, the percentage of received packets for the first $5 \mathrm{~km}$ was higher than $90 \%$. This is a good indicator for a warm-cloud monitoring system where the intended observation heights are between 1 and $2 \mathrm{~km}$ with much lower fluctuation velocities.

The communication technology was also used to demonstrate that the materials used for the bioenvelope of the radioprobe is sufficiently transparent to radio waves and does not hamper the electromagnetic transmission; that said, this study will be fully described in a future paper related to the biodegradable balloon development.

\subsection{Sensors Testing and Validation}

For the purpose of properly calibrating and validating the temperature and humidity sensors' response, a set of tests were carried out in the Applied Thermodynamics Laboratory of the Italian National Metrology Institute (INRiM). A climatic chamber Kambic KK190 CHLT specifically developed for meteorology and climate metrology was used [49]. It allows temperature regulation in the range from $-40{ }^{\circ} \mathrm{C}$ to $180{ }^{\circ} \mathrm{C}$ and relative-humidity control in the range from $10 \%$ to $98 \% \mathrm{RH}$. The reference temperature values were obtained through four platinum resistance thermometers (Pt100) calibrated in INRiM laboratory placed inside the climatic chamber. Pt100 are read using external precision SuperThermometer FLUKE 1594a. The reference humidity value was obtained with a Delta Ohm humidity and temperature probe calibrated at INRiM connected to a datalogger model HD27.17TS. The uncertainty of the Pt100 ranges from $0.011^{\circ} \mathrm{C}$ for positive temperatures and $0.020{ }^{\circ} \mathrm{C}$ for negative temperatures. The total uncertainty of the Delta Ohm probe declared is $\pm 3 \% \mathrm{RH}$.

In order to test not only the accuracy of the temperature and humidity radioprobe sensors but also to have an idea of the possible spread of their behavior, three radioprobe electronic boards were used for this experiment. They were placed inside the climatic chamber, together with reference temperature sensors and humidity probes for comparison purposes. The temperature and relative-humidity measurements from the BME280 were extracted through reading commands implemented in the microcontroller through the $\mathrm{I}^{2} \mathrm{C}$ communication interface at a sampling frequency of $1 \mathrm{~Hz}$.

The climate chamber was set at temperature of $+20^{\circ} \mathrm{C}$ and a relative humidity of $30 \%$ $\mathrm{RH}$ as initial configuration. Then, additional controlled variations of chamber environment in terms of temperature and humidity were applied. In the first test, small incremental steps of $2{ }^{\circ} \mathrm{C}$ in temperature were realized (keeping $\mathrm{RH}$ at $30 \%$ ) until reaching $\mathrm{T}=+24{ }^{\circ} \mathrm{C}$, each one for a time span of approximately $30 \mathrm{~min}$. After that the climatic chamber was configured to provide larger controlled variations in temperature starting from the current set values $\mathrm{T}=+24{ }^{\circ} \mathrm{C}, \mathrm{RH}=30 \%$ until reaching $-5,0$ and $10{ }^{\circ} \mathrm{C}$. Temperature steps need a time span of approximately $1 \mathrm{~h}$ each to obtain temperature stability of the whole system. This temperature cycle was done in order to simulate conditions faced by the radioprobes on site. Although warm clouds are composed only of liquid water having temperatures above $0{ }^{\circ} \mathrm{C}\left(32^{\circ} \mathrm{F}\right)$, the cycle also included negative temperature values to test the sensors performance under extreme situations. The measurement results obtained in the second test are shown in Figure 7. 


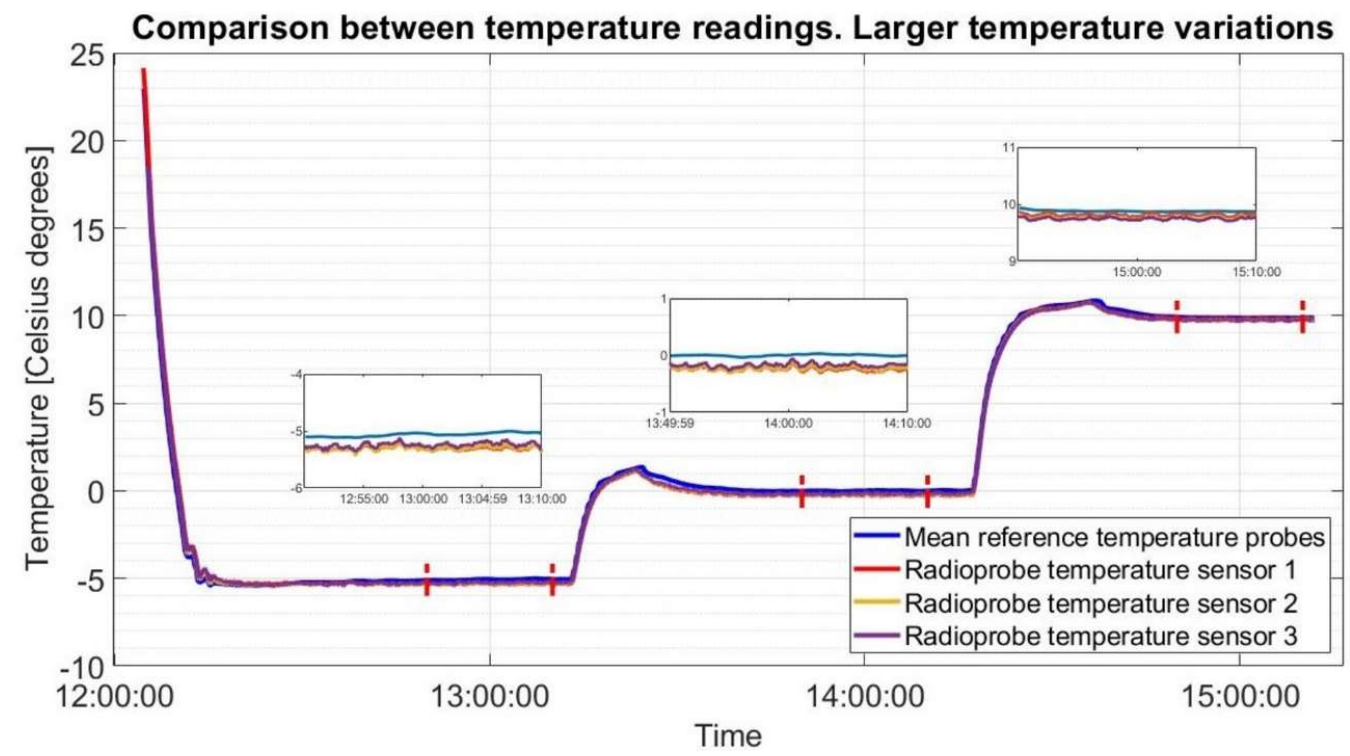

Figure 7. Comparison of temperature measurements between reference temperature sensors and radioprobe sensors. Climatic chamber is set to provide controlled variations in temperature starting from $\mathrm{T}=+24{ }^{\circ} \mathrm{C}, \mathrm{RH}=30 \%$ until reaching the set points of $\mathrm{T}=-5^{\circ} \mathrm{C}, \mathrm{T}=0{ }^{\circ} \mathrm{C}$, and $\mathrm{T}=10{ }^{\circ} \mathrm{C}$.

In the third test, the relative humidity was changed from $10 \% \mathrm{RH}$ to $20 \%, 40 \%$ and $60 \%$, at a constant temperature of $+30{ }^{\circ} \mathrm{C}$; each step needs a time span of approximately $30 \mathrm{~min}$. In order to statistically compare the obtained data, the Makima interpolation technique, which is an algorithm for one-dimensional interpolation, was used considering, at each set point, approximately 5 min of data selected when temperature and humidity conditions inside the chamber are stable. The statistical results of the second and third tests are shown in Tables 4 and 5 .

As a result of this experiment using a high-precision climatic chamber and calibrated reference sensors, the performance of the radioprobe sensors was evaluated. The behavior of the radioprobe sensors lies between the specifications given by the manufacturer for most of the cases (i.e., temperature accuracy $\pm 1{ }^{\circ} \mathrm{C}$ and relative humidity $\pm 3 \% \mathrm{RH}$ ). There are a few exceptions for the relative-humidity measurements that might be caused by the uncertainties introduced by the reference sensor itself (accuracy of the humidity reference sensor $\pm 3 \% \mathrm{RH})$.

An additional field experiment was carried out to verify the response of the temperature, pressure, and humidity sensor stage nested within the radioprobe board. The data obtained came from the experiment setup using the ARPA sounding system already described in Section 4.1: antenna matching and data transmission ranges. The fully operational mini radioprobe was fixed to the front side of the reference Vaisala RS41-SG radiosonde case with the help of a nonconductive adhesive tape. It was constantly measuring, processing, packing, and transmitting the information to the base station located on the ground. The reference probe incorporated a temperature sensor using a linear resistive platinum technology, a humidity sensor integrating humidity, and additional temperature sensing elements, and a GPS receiver allowing the derivation of pressure, height, and wind data [50]. Regarding the accuracy provided by the reference instrument, the uncertainties declared for sounding are $0.3{ }^{\circ} \mathrm{C}$ for temperature measurements (below 16 $\mathrm{km}), 4 \% \mathrm{RH}$ for humidity measurements, and $1.0 \mathrm{hPa} / 0.5 \mathrm{hPa}$ for pressure measurements (for pressure values greater that $100 \mathrm{hPa}$ ). In order to statistically compare the obtained data, the set of measurements considered for the analysis corresponds to the interval up to which the percentage of received packets was greater than $90 \%$. At this point, the straight distance between the flying system and the base station was approximately $5 \mathrm{~km}$. The measurement results obtained are shown in Figure 8. The statistical results of this test are shown in Table 6. 


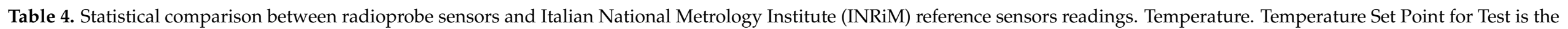
temperature set to the climatic chamber.

\begin{tabular}{|c|c|c|c|c|c|c|c|c|c|c|}
\hline \multirow[b]{2}{*}{$\begin{array}{l}\text { Temperature } \\
\text { Set Point for } \\
\text { Test }\left[{ }^{\circ} \mathrm{C}\right]\end{array}$} & \multirow{2}{*}{$\begin{array}{c}\text { Temperature } \\
\text { Measured by } \\
\text { Reference Sensors } \\
\text { (Mean) }\left[{ }^{\circ} \mathrm{C}\right]\end{array}$} & \multicolumn{3}{|c|}{ Radioprobe 1} & \multicolumn{3}{|c|}{ Radioprobe 2} & \multicolumn{3}{|c|}{ Radioprobe 3} \\
\hline & & Mean $\left[{ }^{\circ} \mathrm{C}\right]$ & $\begin{array}{c}\text { Mean Error }{ }^{1} \\
{\left[{ }^{\circ} \mathrm{C}\right]}\end{array}$ & $\begin{array}{c}\text { Standard } \\
\text { Deviation }{ }^{2} \\
{\left[{ }^{\circ} \mathrm{C}\right]}\end{array}$ & Mean $\left[{ }^{\circ} \mathrm{C}\right]$ & $\begin{array}{c}\text { Mean Error }{ }^{1} \\
{\left[{ }^{\circ} \mathrm{C}\right]}\end{array}$ & $\begin{array}{c}\text { Standard } \\
\text { Deviation }{ }^{2} \\
{\left[{ }^{\circ} \mathrm{C}\right]}\end{array}$ & Mean $\left[{ }^{\circ} \mathrm{C}\right]$ & $\begin{array}{c}\text { Mean Error }{ }^{1} \\
{\left[{ }^{\circ} \mathrm{C}\right]}\end{array}$ & $\begin{array}{c}\text { Standard } \\
\text { Deviation }{ }^{2} \\
{\left[{ }^{\circ} \mathrm{C}\right]}\end{array}$ \\
\hline-5 & -5.063 & -5.31 & 0.25 & 0.04 & -5.30 & 0.24 & 0.04 & -5.25 & 0.18 & 0.04 \\
\hline 0 & 0.002 & -0.25 & 0.25 & 0.03 & -0.23 & 0.23 & 0.03 & -0.17 & 0.18 & 0.03 \\
\hline 10 & 9.878 & 9.82 & 0.065 & 0.02 & 9.75 & 0.13 & 0.03 & 9.74 & 0.13 & 0.02 \\
\hline
\end{tabular}

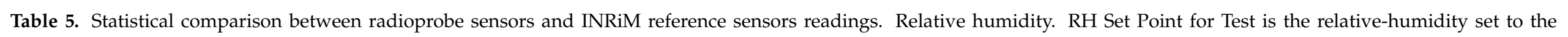
climatic chamber.

\begin{tabular}{|c|c|c|c|c|c|c|c|c|c|c|}
\hline \multirow[b]{2}{*}{$\begin{array}{c}\text { RH Set Point } \\
\text { for Test } \\
{[\% \mathrm{RH}]}\end{array}$} & \multirow[b]{2}{*}{$\begin{array}{l}\text { RH Measured by } \\
\text { Reference Sensors } \\
\text { (mean) [\%RH] }\end{array}$} & \multicolumn{3}{|c|}{ Radioprobe 1} & \multicolumn{3}{|c|}{ Radioprobe 2} & \multicolumn{3}{|c|}{ Radioprobe 3} \\
\hline & & $\begin{array}{c}\text { Mean } \\
\text { [\%RH] }\end{array}$ & $\begin{array}{c}\text { Mean Error }{ }^{1} \\
{[\% \mathrm{RH}]}\end{array}$ & $\begin{array}{c}\text { Standard } \\
\text { Deviation }^{2} \\
{[\% \mathrm{RH}]}\end{array}$ & $\begin{array}{c}\text { Mean } \\
\text { [\%RH] }\end{array}$ & $\begin{array}{c}\text { Mean Error } 1 \\
{[\% \mathrm{RH}]}\end{array}$ & $\begin{array}{c}\text { Standard } \\
\text { Deviation }^{2} \\
\text { [\%RH] }\end{array}$ & $\begin{array}{c}\text { Mean } \\
{[\% R H]}\end{array}$ & $\begin{array}{c}\text { Mean Error }{ }^{1} \\
{[\% \mathrm{RH}]}\end{array}$ & $\begin{array}{c}\text { Standard } \\
\text { Deviation }{ }^{2} \\
{[\% \mathrm{RH}]}\end{array}$ \\
\hline 10 & 10.50 & 13.12 & 2.62 & 0.01 & 14.74 & 4.24 & 0.02 & 14.16 & 3.66 & 0.02 \\
\hline 20 & 19.75 & 19.85 & 0.09 & 0.08 & 21.35 & 1.60 & 0.17 & 21.09 & 1.34 & 0.18 \\
\hline 40 & 37.68 & 35.31 & 2.37 & 0.10 & 35.64 & 2.04 & 0.12 & 36.06 & 1.62 & 0.12 \\
\hline 60 & 59.70 & 56.13 & 3.57 & 0.07 & 54.53 & 5.17 & 0.05 & 55.69 & 4.01 & 0.04 \\
\hline
\end{tabular}

${ }^{1}$ Relative humidity difference between reference sensor reading and the radioprobe sensor reading. ${ }^{2}$ Standard deviation of radioprobe relative-humidity reading. 

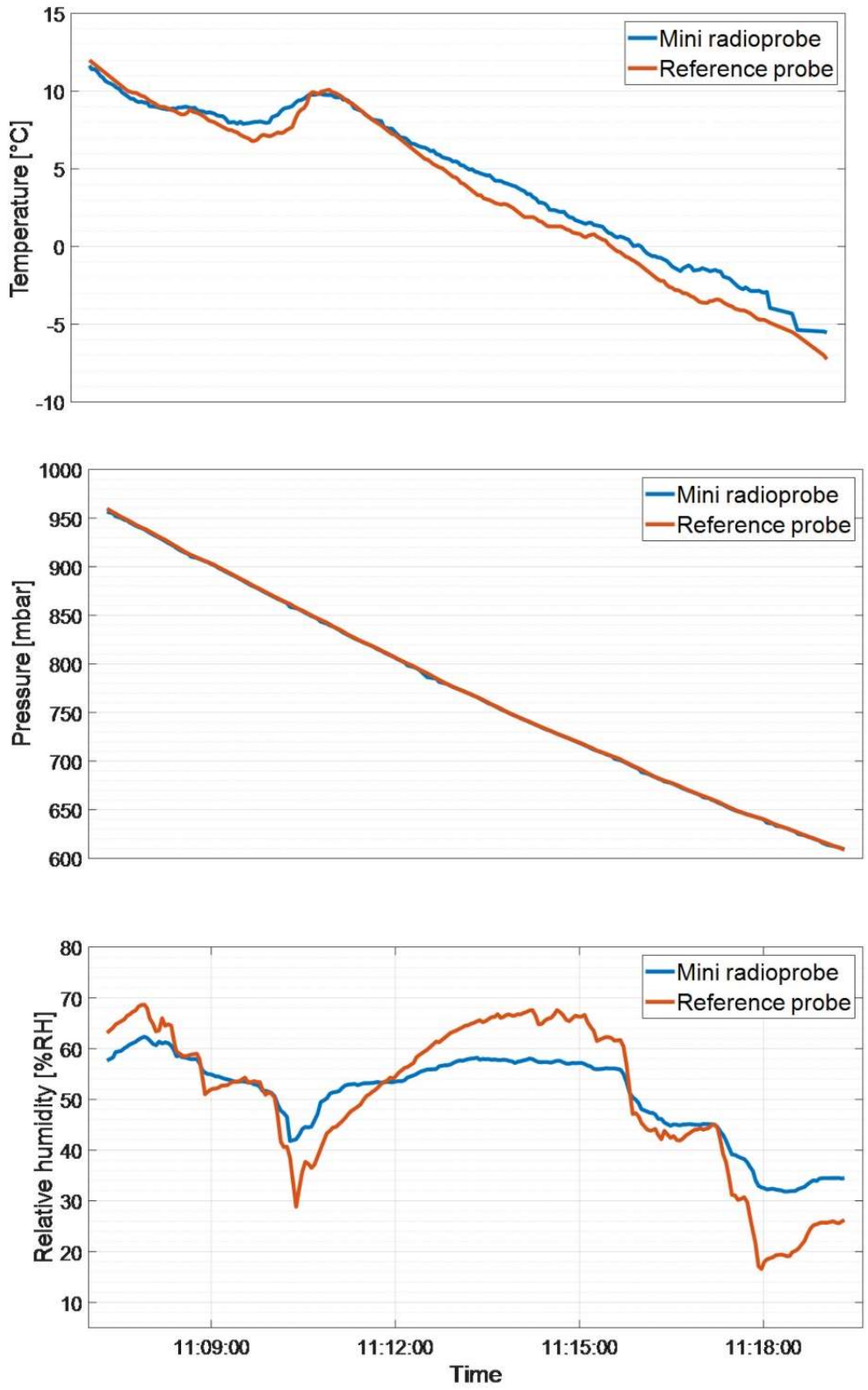

Figure 8. Comparison of temperature, pressure, and relative-humidity measurements between the Regional Agency for the Protection of the Environment (ARPA) reference sonde sensors and the radioprobe sensors.

Table 6. Statistical comparison between radioprobe sensor readings and ARPA reference sonde readings.

\begin{tabular}{ccccc}
\hline & \multirow{2}{*}{\begin{tabular}{c} 
VAISALA Reference \\
Sensor Measurements \\
\cline { 3 - 5 }
\end{tabular}} & \multicolumn{3}{c}{ Radioprobe Measurements } \\
\cline { 3 - 5 } & (Mean) & Mean & $\begin{array}{c}\text { Mean } \\
\text { Error }{ }^{\mathbf{1}}\end{array}$ & $\begin{array}{c}\text { Standard } \\
\text { Deviation }^{2}\end{array}$ \\
\hline Temperature [ $\left.{ }^{\circ} \mathbf{C}\right]$ & 4.16 & 4.93 & 0.87 & 0.56 \\
Pressure [mbar] & 774.14 & 773.53 & 0.63 & 0.58 \\
Relative humidity [\%RH] & 50.74 & 50.86 & 5.53 & 3.71 \\
\hline
\end{tabular}

${ }^{1}$ Difference between reference sensor reading and the radioprobe sensor reading. ${ }^{2}$ Standard deviation of radioprobe sensor readings.

As a result of this experiment using a VAISALA radiosonde as a reference, the performance of the radioprobe's temperature, humidity, and pressure sensor block was evaluated. From Figure 8, it is possible to observe some differences between the measurements pro- 
vided by the radioprobe sensors and the reference instrument. These effects could have been produced by the position itself of the mini radioprobe onto the case containing the reference probe. Due to the lack of space available for placing the radioprobe and for avoiding its fall during the flight, it was tightly attached to the reference probe leading to potential undesired effects. For instance, being in direct contact with the main body of reference instrument case, the energy dissipated by the reference probe could have affected the radioprobe measurements. Also, since the airflow in direction to the vent hole of the TPH sensors was partially obstructed, the exchange of sufficient air was not possible, contributing to errors in the measurements. Notwithstanding the aforementioned issues and considering the limited resources in the design (e.g., small size, ultralight weight, low-power and low-cost sensors), it can be said from the obtained results that the performance of the TPH radioprobe sensors is good enough for the purpose of the radioprobe development. Overall, considering the uncertainties introduced by the reference sensors, the behavior of the TPH radioprobe sensors lies within the specifications given by the manufacturer, as can be seen in Table 6 .

Future experiments will include a different setup of the instruments to overcome the problems encountered during the execution of this field experiment.

To validate the radioprobe's positioning and tracking system, it was compared to GPS data from a smartphone device. This test was carried out in an open area within the city of Turin. The system setup included a radioprobe measuring and partially processing the readings from the IMU sensors (accelerometer, gyroscope, and magnetometer), and gathering the geolocation and time updates from the GNSS receiver. The radioprobe was configured in order to provide a GNSS sensor update every $2 \mathrm{~s}$ and two IMU sensor updates every second. It was connected via serial port to a portable PC for data logging. Additionally, an Android-based smartphone model Samsung Galaxy S8+ executing a GNSS logger application for recording the position and path followed was used. This application provided positioning updates for every second.

For this experiment, the radioprobe and the smartphone simultaneously recorded data during a walk. Before starting the measurements, the calibration of the IMU sensors was performed to ensure that the readings and the output of the prefiltering process executed at the radioprobe side were accurate. While being at rest, the bias errors and noise introduced by the accelerometer, gyroscope, and magnetometer were properly identified. In addition, since the GNSS update frequencies between the reference and radioprobe were different, the IMU readings were used to predict positioning information for the intermediate time steps. To this end, the IMU sensor data were processed using Madgwick filtering, which is an orientation algorithm to describe orientation in three-dimensions [51], to get accelerations in NED (north, east, and down) absolute frame. This frame is useful for the postprocessing analysis to predict the radioprobe's position along its trajectory. Thus, acceleration data in absolute frame can be combined with LLA (latitude, longitude, and altitude) absolute positioning data coming from the GNSS server. In this way, it is possible to have five (one GNSS update and four predictions with IMU data) positioning information for every $2 \mathrm{~s}$. The raw acceleration data along $\mathrm{x}, \mathrm{y}$, and $\mathrm{z}$ directions in the radioprobe's body frame and the converted acceleration in absolute frame after applying the orientation filter are shown in Figure 9. Since the experiment was performed in a horizontal plane, it is possible to see the north and east accelerations around zero, except for small fluctuations due to walk maneuver. Instead, for the down direction, the acceleration was around $10 \mathrm{~m} / \mathrm{s}^{2}$ because of gravity. 

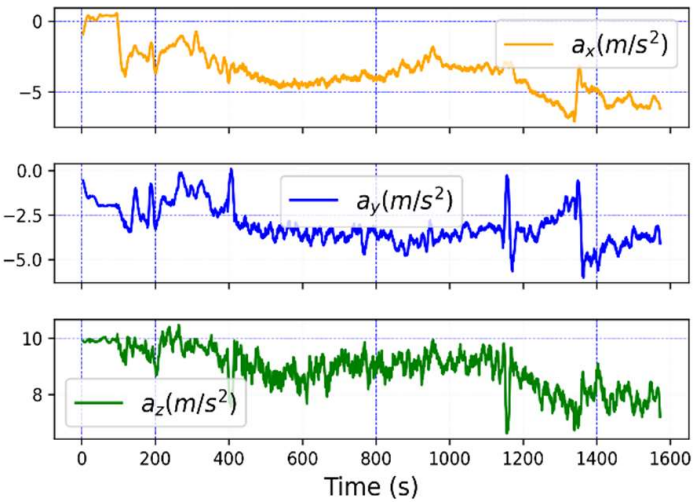

(a)
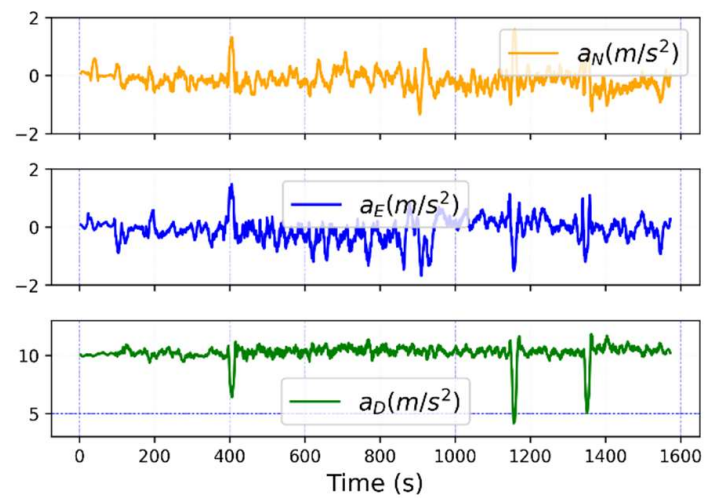

(b)

Figure 9. Absolute acceleration: (a) raw acceleration in radioprobe's body frame; (b) filtered acceleration in NED (north, east, and down) frame.

During the experiment, the total traveled distance from the starting to the final points was approximately $1.6 \mathrm{~km}$ for a time span of approximately $30 \mathrm{~min}$. The trajectory recorded by both systems together with the comparison between trajectories along north (Latitude) and east (longitude) directions are shown in Figure 10. The statistical results of the positioning sensors accuracy (IMU and GNSS) are shown in Table 7.

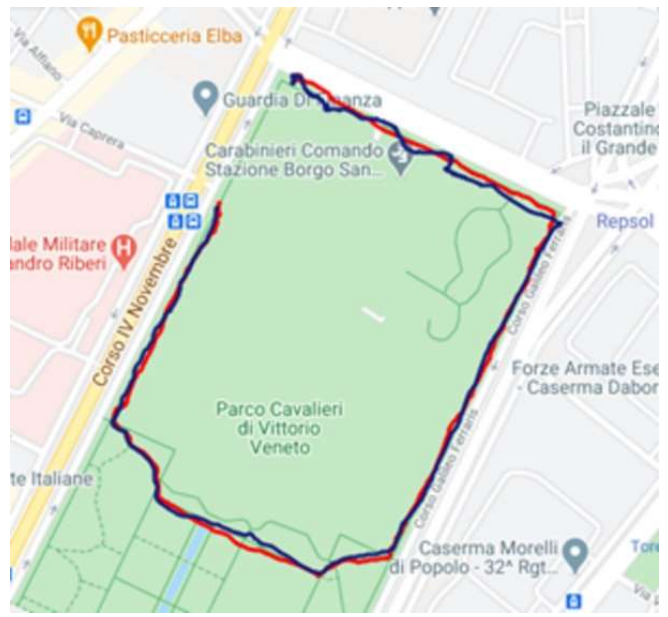

(a)
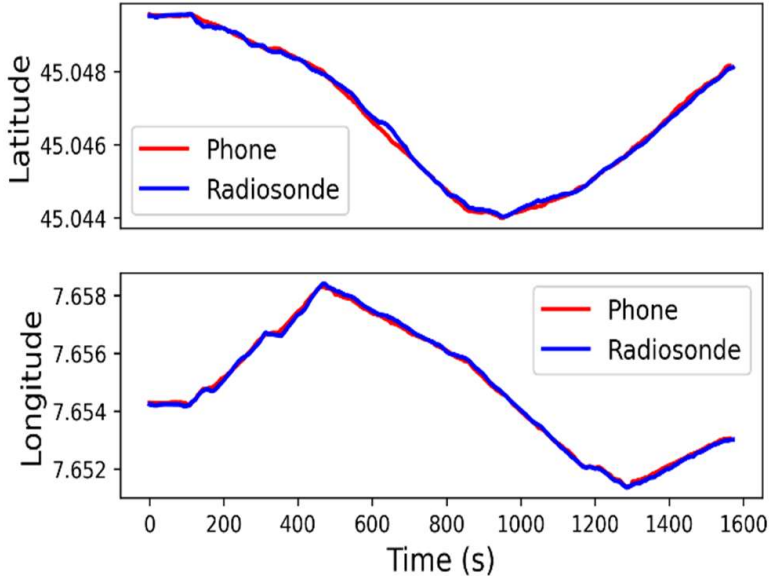

(b)

Figure 10. Trajectory recorded by the radioprobe (blue line) and the smartphone GPS logger (red line) during a walk: (a) trajectory comparison displayed on a map; (b) latitude and longitude comparison between the radioprobe and the smartphone GPS logger in function of time.

From the obtained results, it is possible to verify the reasonable performance of the positioning and tracking radioprobe sensor unit considering the limited resources at the radioprobe side (e.g., low power, low memory availability, light weight and not-expensive sensors). To overcome these challenges, the reduction of the IMU sampling rate and the activation of a GNSS super-saving mode (E-mode) are among the strategies used. The partially processed data generated at this stage constitute the input for the further postprocessing step executed at the ground level to reconstruct the trajectory followed by the mini radioprobes. 
Table 7. Statistical results of positioning sensor accuracy (internal measurement unit (IMU) and Global Navigation Satellite System (GNSS)) during the experiment.

\begin{tabular}{cccc}
\hline Sensor & & Offset (Sensor Bias) & Standard Deviation \\
\hline \multirow{2}{*}{ Accelerometer $\left[\mathrm{m} / \mathrm{s}^{2}\right]$} & $\mathrm{x}$ & 0.26 & 0.025 \\
& $\mathrm{y}$ & 0.21 & \\
\hline \multirow{2}{*}{ Gyroscope $[$ degree $/ \mathrm{s}]$} & $\mathrm{z}$ & -0.45 & 0.1 \\
& $\mathrm{x}$ & 1.03 & \\
\hline \multirow{2}{*}{ Magnetometer } & $\mathrm{y}$ & 1.22 & 4.2 \\
[mGauss] & $\mathrm{z}$ & 8.80 & \\
& $\mathrm{x}$ & 84.56 & $5.73 \times 10^{-5}$ \\
GNSS [degrees] & $\mathrm{y}$ & -211.68 & $7.40 \times 10^{-5}$ \\
\hline
\end{tabular}

An additional experiment to validate the positioning and tracking radioprobe sensor unit was conducted. Although the balloon's performance analysis is not the purpose of this work, we carried out a preliminary tethered-balloon test at low altitude (30-50 m) to expose the radioprobe to real atmospheric air fluctuation and verify the fluctuation detection ability of the tiny radioprobe when flying. This test was carried out at Parco Piemonte, which is a wide tree-free park located at the south area of Turin. The field measurement consisted of a point-to-point dynamic network configuration including a fully operational radioprobe collecting and transmitting the about-flight information, and a ground station receiving, storing, and postprocessing the received messages. The mini radioprobe was inserted in the middle of the helium-filled biodegradable balloon and released into the low atmosphere. In order to not lose the measuring system, the balloon was attached to a long thin thread and held by one of the participants. The radioprobe's transceiver was programmed to provide an output power of $14 \mathrm{dBm}$ at a central frequency of $865.2 \mathrm{MHz}$, spreading factor of 10, and bandwidth of $125 \mathrm{kHz}$. The receiver was placed close to the ground at an approximated height of $1 \mathrm{~m}$ and at an approximate distance of $25 \mathrm{~m}$ from the initial balloon release point. Both the transmitter and the receiver were in LOS during the execution of the experiment. The trajectory followed by the radioprobe during the flight is shown in Figure 11.

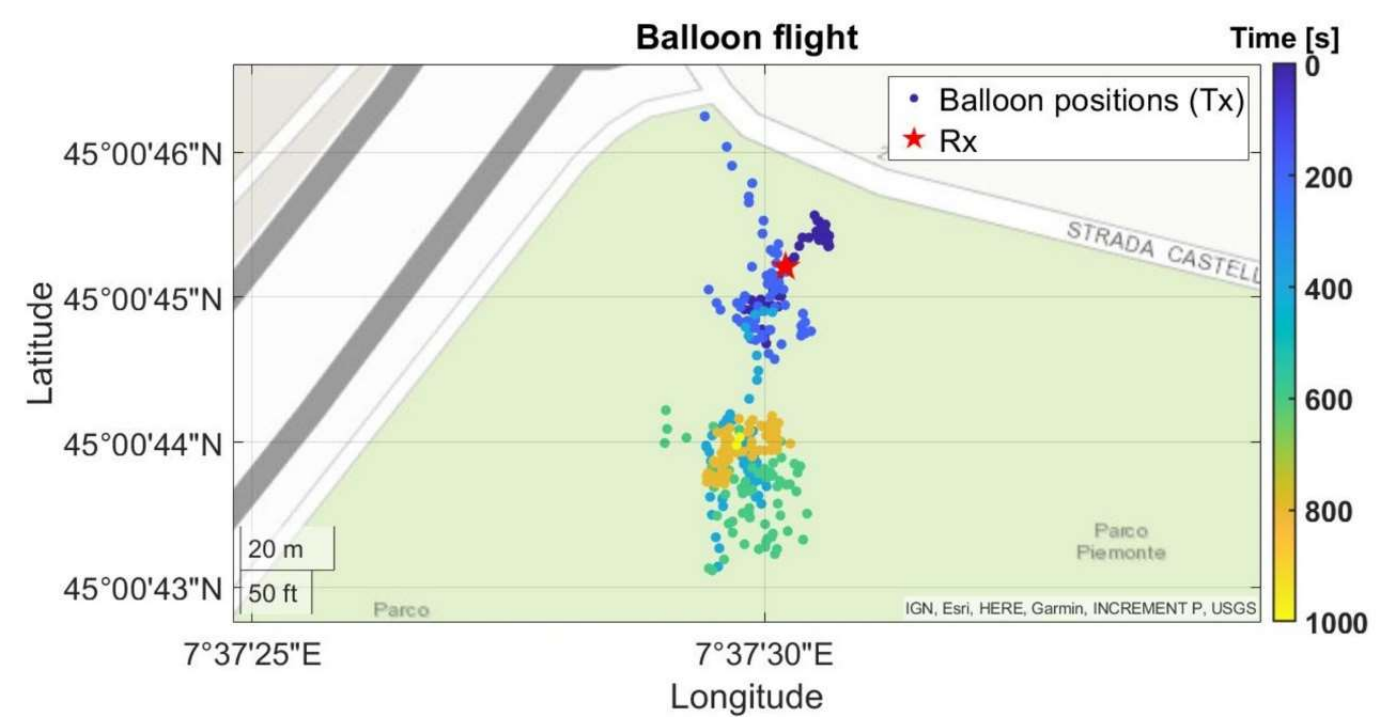

Figure 11. Low-atmosphere trajectory of the fully operational radioprobe inserted in a helium-filled biodegradable balloon, displayed on a map. The color bar indicates the elapsed time. 
The IMU measurements (acceleration, angular rate, and magnetic field) are displayed in Figure 12.
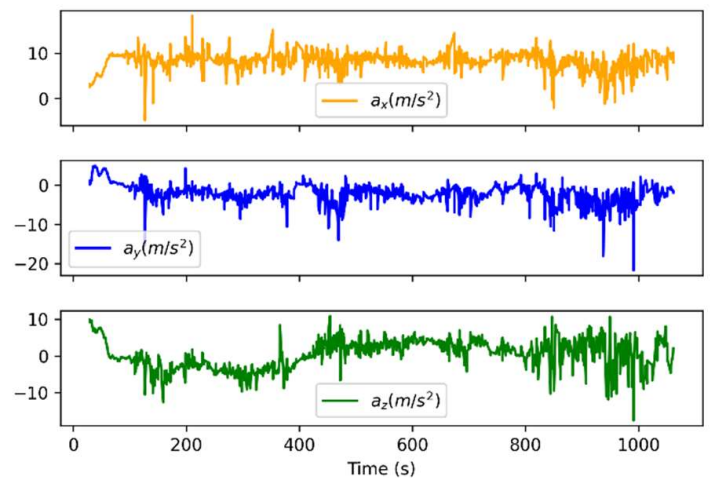

(a)
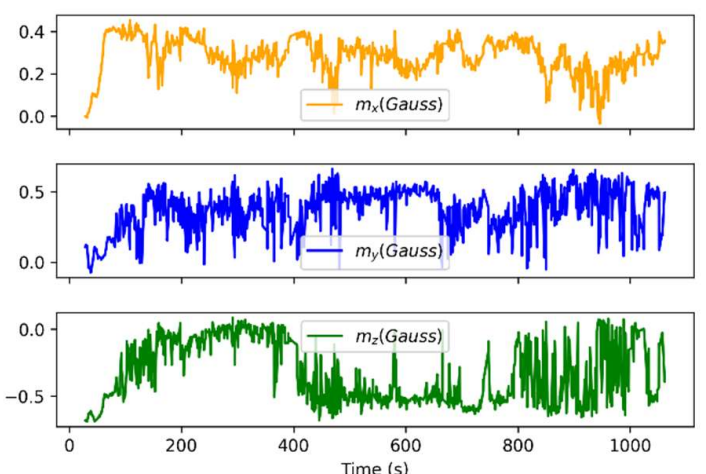

(b)

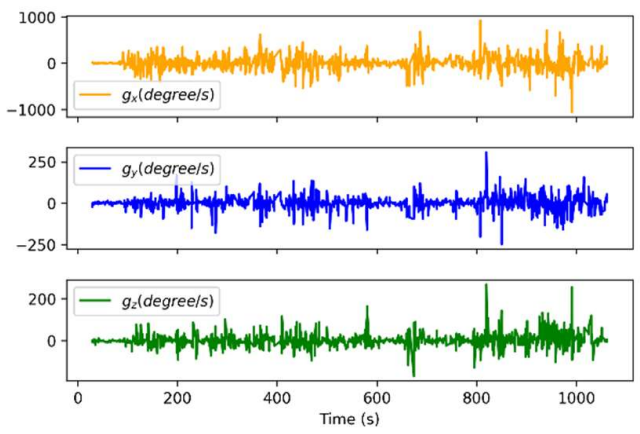

(c)

Figure 12. Radioprobe sensor measurements sent to the ground station for postprocessing purposes: (a) raw acceleration measured by the radioprobe sensors during the flight; (b) raw magnetic field measured by the radioprobe sensors during the flight; and (c) raw angular rate measured by the radioprobe sensors during the flight.

As a result of this experiment, the fully operational radioprobe was tested in a lowatmosphere open environment. The obtained results show the good radioprobe capacity to detect acceleration, angular rate, and magnetic-field fluctuations while flying inside the balloon in a dynamic environment. In addition, all the transmitted packets sent by the moving instrument were correctly received at the ground station. The SNR values ranged from +9 to $-12 \mathrm{~dB}$ and the RSSI of the packets from -65 to $-109 \mathrm{dBm}$.

\subsection{Power-Consumption Analysis}

Power consumption is a key factor determining the radioprobe's life. In order to save energy, different solutions were adopted to extend the battery lifetime, according to the following power management strategies:

- Every single electronic component populating the radioprobe PCB was selected considering its power requirements to minimize the total energy consumption of the system.

- The readings obtained from the TPH and positioning/tracking sensor stages were partially processed at the radioprobe side to reduce the amount of information to be transmitted to ground stations.

- The number of packets to be transmitted were minimized by packing together two or more messages in a single data frame. In this way, the time-on-air of a single packet is higher, however, the number of transmissions is lower, hence saving power. 
- Because the GNSS is the most power-consuming sensor, it was periodically switched on and off to provide only the necessary information to update the reference position of the last Kalman's filter output at the ground-station level.

- The GNSS receiver was configured to work in the super E-mode, which provides a good trade-off between current consumption and performance. This mode allows saving 3 times power compared with a traditional u-blox GNSS operating in full power mode [46], and in addition, the receiver can automatically duty-cycle the external LNA to further reduce power usage.

As a result, the total current consumption of the radioprobe, which depends on the task in execution and the programmed transmission power, was properly measured. It may vary from an average value of approximately $90 \mathrm{~mA}$ to a maximum value of $123 \mathrm{~mA}$ when all of the system is operating: the GNSS receiver is in acquisition mode, the radioprobe is transmitting a packet, the microcontroller is executing instructions, and the remaining sensors are taking measurements. In external conditions, the battery can supply energy to the radioprobe for approximately $60 \mathrm{~min}$.

\section{Conclusions and Future Work}

This paper presents a novel method based on a WSN system for in situ measuring of the influence of small-scale turbulence in cloud formation by means of the design and implementation of an innovative ultralight expendable radioprobe. The integration of different areas of research (for instance, low-power wireless sensor network communications; sensors and instrumentation for atmospheric measurements; sensors and instrumentation for trajectory tracking; antenna embedding and matching; and electronic board design) allowed for the development of a complete and reliable system able to measure and transfer in an effective way atmospheric-based data through a long-range power-saving telemetry link to ground stations.

The radioprobes are conceived to sense temperature, pressure, and humidity of the cloud and ambient air. Also, they are aimed to measure velocity and acceleration fluctuations of the balloon motion along its trajectory. These fluctuations will be mainly analyzed through temporal and spatial-spectral analysis. From this, it can be understood how fluctuations in frequency, wavelength, and kinetic energy are necessary concepts, and in fact commonly employed, to describe the properties of lukewarm clouds and surrounding subsaturated air systems.

Outcomes from the different field measurements confirmed that the newly developed radioprobe device performs well and provides accurate information while keeping unique features for an instrumented weather balloon such as compact size, ultralight weight, lowcost and low energy consumption. Each tiny probe can communicate correctly up to $5 \mathrm{~km}$ of distance, which is a transmission range enough for a warm-cloud environment of heights between 1 and $2 \mathrm{~km}$. In agreement with the atmospheric spectra deduced from in-field measurements [52-56], in particular within the range concerning the small spatial scale (below $10 \mathrm{~km}$ ), the sampling rate of the measured quantities is envisaged to reconstruct signals with frequencies in the range between $10^{-4}$ and $1 \mathrm{~Hz}$. Considering the type of instrumentation embedded and the size associated to the radioprobes, it can be said that these devices can measure wavelengths in the order of $1 \mathrm{~m}$ up to few kilometers, velocities from $30-50 \mathrm{~cm} / \mathrm{s}$ up to $5-6 \mathrm{~m} / \mathrm{s}$, and accelerations up to $\pm 4 \mathrm{~g}$. In fact, the solid-state sensor producer datasheets $[45,46]$ state that the IMU is capable of detecting linear accelerations up to $\pm 4 \mathrm{~g}$, and the GNSS receiver can work up to $4 \mathrm{~g}$, at altitudes up to $50 \mathrm{~km}$ and velocities up to $500 \mathrm{~m} / \mathrm{s}$ with the current configuration set in both devices. These findings suggest that these tiny radioprobes when embedded in a biodegradable balloon of diameter of 30 $\mathrm{cm}$ can behave as quasi-Lagrangian tracers of also small-scale turbulent fluctuations once released into warm clouds.

Based on the findings of the present paper, future work includes further miniaturization and weight optimization of the first radioprobe version here presented. In addition, the new electronic design will include a daughter board populated with the TPH sensors, 
which will be placed outside the enclosure to be in direct contact with the atmosphere and measure the physical parameters of interest. Furthermore, since the final goal of this research project is the generation of an in-field cloud Lagrangian dataset, the upcoming experiments will include a bunch of complete radioprobes (electronics and enclosure) working as a single system and simultaneously transmitting the collected cloud data to the ground stations for final postprocessing tasks. Finally, for the purpose of completely recovering the power spectrum of the physical quantities under study inside clouds (temperature, pressure, humidity, and acceleration), future experiments could include the use of better-performing batteries (i.e., military grade), which will require the overcoming of acquisition and administrative procedures.

Author Contributions: Conceptualization, M.E.P.Q., E.G.A.P., D.T., and F.C.; methodology, M.E.P.Q. and M.A.; software, M.E.P.Q. and S.A.; validation, M.E.P.Q., S.A., A.M., and C.M.; formal analysis, M.E.P.Q., S.A., A.M., and C.M.; investigation, M.E.P.Q. and M.A.; experimental design, M.E.P.Q., A.M., C.M., and D.T.; resources, M.A., A.M., C.M., and E.G.A.P.; data curation, M.E.P.Q.; writing-original draft preparation, M.E.P.Q.; writing-review and editing, E.G.A.P., D.T., and F.C.; visualization, M.E.P.Q. and S.A.; supervision, E.G.A.P., D.T., and F.C.; project administration, D.T.; funding acquisition, D.T. All authors have read and agreed to the published version of the manuscript.

Funding: This project has received funding from the Marie Sklodowska-Curie Actions (MSCA) under the European Union's Horizon 2020 research and innovation program (grant agreement $n^{\circ} 675675$ ).

Institutional Review Board Statement: Not applicable.

Informed Consent Statement: Not applicable.

Data Availability Statement: Data will be shortly available in the publicly accessible repository of the Horizon MSCA ITN ETN COMPLETE, see www.complete-h2020.eu (accessed on 1 February 2021). The data presented in this study are openly available in [repository name e.g., H2020 ITN-ETNCOMPLETE] at [doi...to appear], reference number [to be obtained].

Acknowledgments: The authors would like to thank the Istituto Nazionale di Ricerca Metrologica (INRiM) for supporting the experimental measurements held at the Applied Thermodynamics Laboratory. The authors would like to thank the Regional Agency for the Protection of the Environment (ARPA) of the Piedmont Region of Italy, specially to Luca Tomassone, for supporting the experimental measurements using their national atmospheric sounding system. The authors would like to thank the Istituto Italiano di Tecnologia (IIT) for supporting the development of the biodegradable balloons at the Smart Materials Department. The authors would like to thank Emilio Giovanni Perona and Silvano Bertoldo for providing useful suggestions during the conception and evolution of this research work. The authors would like to thank Athanassia Athanassiou, Giovanni Perotto, and Giovanni Cipri for designing, characterizing, and developing the probe envelope green material.

Conflicts of Interest: The authors declare no conflict of interest.

\section{References}

1. Siebert, H.; Franke, H.; Lehmann, K.; Maser, R.; Saw, E.W.; Schell, D.; Shaw, R.A.; Wendisch, M. Probing Finescale Dynamics and Microphysics of Clouds with Helicopter-Borne Measurements. Bull. Am. Meteorol. Soc. 2006, 87, 1727-1738. [CrossRef]

2. Clouds in the Perturbed Climate System: Their Relationship to Energy Balance, Atmospheric Dynamics, and Precipitation; Strüngmann Forum Reports; Heintzenberg, J.; Charlson, R.J. (Eds.) MIT Press: Cambridge, MA, USA, 2009; ISBN 978-0-262-01287-4.

3. Intergovernmental Panel on Climate Change Clouds and Aerosols. Climate Change 2013-The Physical Science Basis: Working Group I Contribution to the Fifth Assessment Report of the Intergovernmental Panel on Climate Change; Cambridge University Press: Cambridge, UK, 2014; pp. 571-658. ISBN 978-1-107-05799-9.

4. Bodenschatz, E.; Malinowski, S.P.; Shaw, R.A.; Stratmann, F. Can We Understand Clouds Without Turbulence? Science 2010, 327, 970-971. [CrossRef] [PubMed]

5. Stechmann, S.N.; Stevens, B. Multiscale Models for Cumulus Cloud Dynamics. J. Atmos. Sci. 2010, 67, 17. [CrossRef]

6. CORDIS; European Commission. Cloud-MicroPhysics-Turbulence-Telemetry: An Inter-Multidisciplinary Training Network for Enhancing the Understanding and Modeling of Atmospheric Clouds. COMPLETE Project. H2020. Available online: https:/ / cordis.europa.eu/project/id/675675 (accessed on 23 November 2020).

7. Devenish, B.J.; Bartello, P.; Malinowski, S.P.; Reeks, M.W.; Vassilicos, J.C. Droplet Growth in Warm Turbulent Clouds. Q. J. R. Meteorol. Soc. 2012, 138, 1401-1429. [CrossRef] 
8. MacPherson, J.I.; Isaac, G.A. Turbulent Characteristics of Some Canadian Cumulus Clouds. J. Appl. Meteorol. Climatol. 1977, 16, 81-90. [CrossRef]

9. Cooper, K.B.; Chattopadhyay, G. Submillimeter-Wave Radar: Solid-State System Design and Applications. IEEE Microw. Mag. 2014, 15, 51-67. [CrossRef]

10. Hubbert, J.C.; Wilson, J.W.; Weckwerth, T.M.; Ellis, S.M.; Dixon, M.; Loew, E. S-Pol's Polarimetric Data Reveal Detailed Storm Features (and Insect Behavior). Bull. Am. Meteorol. Soc. 2018, 99, 2045-2060. [CrossRef]

11. Siebert, H.; Lehmann, K.; Wendisch, M. Observations of Small-Scale Turbulence and Energy Dissipation Rates in the Cloudy Boundary Layer. J. Atmos. Sci. 2006, 63, 16. [CrossRef]

12. Lehmann, K.; Siebert, H.; Shaw, R.A. Homogeneous and Inhomogeneous Mixing in Cumulus Clouds: Dependence on Local Turbulence Structure. J. Atmos. Sci. 2009, 66, 3641-3659. [CrossRef]

13. Malinowski, S.P.; Gerber, H.; Jen-La Plante, I.; Kopec, M.K.; Kumala, W.; Nurowska, K.; Chuang, P.Y.; Khelif, D.; Haman, K.E. Physics of Stratocumulus Top (POST): Turbulent Mixing across Capping Inversion. Atmos. Chem. Phys. 2013, 13, 12171-12186. [CrossRef]

14. Hoppel, W.A.; Frick, G.M.; Fitzgerald, J.W.; Wattle, B.J. A Cloud Chamber Study of the Effect That Nonprecipitating Water Clouds Have on the Aerosol Size Distribution. Aerosol Sci. Technol. 1994, 20, 1-30. [CrossRef]

15. Siebert, H.; Shaw, R.A.; Ditas, J.; Schmeissner, T.; Malinowski, S.P.; Bodenschatz, E.; Xu, H. High-Resolution Measurement of Cloud Microphysics and Turbulence at a Mountaintop Station. Atmos. Meas. Tech. 2015, 8, 3219-3228. [CrossRef]

16. Chang, K.; Bench, J.; Brege, M.; Cantrell, W.; Chandrakar, K.; Ciochetto, D.; Mazzoleni, C.; Mazzoleni, L.R.; Niedermeier, D.; Shaw, R.A. A Laboratory Facility to Study Gas-Aerosol-Cloud Interactions in a Turbulent Environment: The $\Pi$ Chamber. Bull. Am. Meteorol. Soc. 2016, 97, 2343-2358. [CrossRef]

17. Kumar, B.; Götzfried, P.; Suresh, N.; Schumacher, J.; Shaw, R.A. Scale Dependence of Cloud Microphysical Response to Turbulent Entrainment and Mixing. J. Adv. Model. Earth Syst. 2018, 10, 2777-2785. [CrossRef]

18. Kumar, B.; Schumacher, J.; Shaw, R.A. Lagrangian Mixing Dynamics at the Cloudy-Clear Air Interface. J. Atmos. Sci. 2014, 71, 2564-2580. [CrossRef]

19. Fletcher, S.J. Observations. In Data Assimilation for the Geosciences; Elsevier: Amsterdam, The Netherlands, 2017; pp. 599-626. ISBN 978-0-12-804444-5.

20. Toschi, F.; Bodenschatz, E. Lagrangian Properties of Particles in Turbulence. Annu. Rev. Fluid Mech. 2009, 41, 375-404. [CrossRef]

21. Richardson, L.F.; Walker, G.T. Atmospheric Diffusion Shown on a Distance-Neighbour Graph. Proc. R. Soc. Lond. Ser. Contain. Pap. Math. Phys. Character 1926, 110, 709-737. [CrossRef]

22. Turbulent Particle Pair Diffusion: A Theory Based on Local and Non-Local Diffusional Processes. Available online: https: / / journals.plos.org/plosone/article?id=10.1371/journal.pone.0202940 (accessed on 23 November 2020).

23. Basso, T.C.; Perotto, G.; Musacchio, C.; Merlone, A.; Athanassiou, A.; Tordella, D. Evaluation of Mater Bi and Polylactic Acid as Materials for Biodegradable Innovative Mini-Radiosondes to Track Small Scale Fluctuations within Clouds. Mater. Chem. Phys. 2020, 253, 123411. [CrossRef]

24. Wick, G.A.; Hock, T.F.; Neiman, P.J.; Vömel, H.; Black, M.L.; Spackman, J.R. The NCAR-NOAA Global Hawk Dropsonde System. J. Atmos. Ocean. Technol. 2018, 35, 1585-1604. [CrossRef]

25. Air Resources Laboratory. Low Altitude Balloon Measurement Platforms. Available online: https://www.arl.noaa.gov/wp_arl/ wp-content/uploads/Review / Posters/Balloon.pdf (accessed on 10 November 2020).

26. National Centers for Environmental Information (NCEI)/National Climatic Data Center (NCDC). Picture Climate: Balloons Aren't Just for Birthdays. Available online: https: / www.ncdc.noaa.gov/news/picture-climate-balloons-aren $\%$ E2\%80\%99t-justbirthdays (accessed on 24 November 2020).

27. Swenson, S.; Argrow, B.; Frew, E.; Borenstein, S.; Keeler, J. Development and Deployment of Air-Launched Drifters from Small UAS. Sensors 2019, 19, 2149. [CrossRef]

28. Markowski, P.M.; Richardson, Y.P.; Richardson, S.J.; Petersson, A. Aboveground Thermodynamic Observations in Convective Storms from Balloonborne Probes Acting as Pseudo-Lagrangian Drifters. Bull. Am. Meteorol. Soc. 2018, 99, 711-724. [CrossRef]

29. Provenzale, A. Transport by coherent barotropic vortices. Annu. Rev. Fluid Mech. 1999, 31, 55-93. [CrossRef]

30. Pasquero, C.; Bracco, A.; Provenzale, A.; Weiss, J.B. Particle Motion in a Sea of Eddies. In Lagrangian Analysis and Prediction of Coastal and Ocean Dynamics; Kirwan, A.D., Jr., Griffa, A., Mariano, A.J., Rossby, H.T., Özgökmen, T., Eds.; Cambridge University Press: Cambridge, MA, USA, 2007; pp. 89-118. ISBN 978-0-521-87018-4.

31. Geerts, B.; Raymond, D.J.; Grubišić, V.; Davis, C.A.; Barth, M.C.; Detwiler, A.; Klein, P.M.; Lee, W.-C.; Markowski, P.M.; Mullendore, G.L.; et al. Recommendations for In Situ and Remote Sensing Capabilities in Atmospheric Convection and Turbulence. Bull. Am. Meteorol. Soc. 2018, 99, 2463-2470. [CrossRef]

32. ATmega328P; 8-Bit AVR Microcontrollers. Available online: https://www.microchip.com/wwwproducts/en/ATmega328p (accessed on 24 November 2020).

33. Raza, U.; Kulkarni, P.; Sooriyabandara, M. Low Power Wide Area Networks: An Overview. IEEE Commun. Surv. Tutor. 2017, 19, 855-873. [CrossRef]

34. Augustin, A.; Yi, J.; Clausen, T.; Townsley, W. A Study of LoRa: Long Range \& Low Power Networks for the Internet of Things. Sensors 2016, 16, 1466. [CrossRef] 
35. Rizzi, M.; Ferrari, P.; Flammini, A.; Sisinni, E. Evaluation of the IoT LoRaWAN Solution for Distributed Measurement Applications. IEEE Trans. Instrum. Meas. 2017, 66, 10. [CrossRef]

36. Hoperf. RFM95W Feature the LoRaTM Long Range Model. Available online: https://www.hoperf.com/modules/lora/RFM95. html (accessed on 24 November 2020).

37. Bertoldo, S.; Paredes, M.; Carosso, L.; Allegretti, M.; Savi, P. Empirical Indoor Propagation Models for LoRa Radio Link in An Office Environment. In Proceedings of the 13th European Conference on Antennas and Propagation (EuCAP), Krakow, Poland, 31 March-5 April 2019; IEEE Xplore: Piscataway, NJ, USA; pp. 1-5.

38. Bertoldo, S.; Carosso, L.; Marchetta, E.; Paredes, M.; Allegretti, M. Feasibility Analysis of a LoRa-Based WSN Using Public Transport. Appl. Syst. Innov. 2018, 1, 49. [CrossRef]

39. Paredes, M.; Bertoldo, S.; Carosso, L.; Lucianaz, C.; Marchetta, E.; Allegretti, M.; Savi, P. Propagation Measurements for a LoRa Network in an Urban Environment. J. Electromagn. Waves Appl. 2019, 33, 2022-2036. [CrossRef]

40. Bertoldo, S.; Lucianaz, C.; Paredes, M.; Allegretti, M.; Carosso, L.; Savi, P. Feasibility Study of LoRa Ad-Hoc Network in an Urban Noisy Environment. In Proceedings of the 18th Mediterranean Microwave Symposium (MMS), Istanbul, Turkey, 31 October-2 November 2018; pp. 357-360.

41. ETSI EN 300 220-2. Short Range Devices (SRD) Operating in the Frequency Range $25 \mathrm{MHz}$ to 1000 MHz. Part 2: Harmonised Standard for Access to Radio Spectrum for Non Specific Radio Equipment. Available online: https:/ /www.etsi.org/deliver/etsi_ en/300200_300299/30022002/03.02.01_60/en_30022002v030201p.pdf (accessed on 23 January 2021).

42. Altium. Via Stitching and Via Shielding. Altium Designer 20.2 User Manual. Available online: https://www.altium.com/ documentation/altium-designer/via-stitching-and-via-shielding-ad (accessed on 24 November 2020).

43. Bosch. Humidity Sensor BME280. Available online: https://www.bosch-sensortec.com/products/environmental-sensors/ humidity-sensors-bme280/ (accessed on 24 November 2020).

44. Liu, Q. A Brief Introduction to Fluid Mechanics, 5th ed.; John Wiley \& Sons: Hoboken, NJ, USA, 1996.

45. ST life. augmented. LSM6DSM. iNEMO Inertial Module: Always-On 3D Accelerometer and 3D Gyroscope. Available online: https: / / www.st.com/en/mems-and-sensors/lsm6dst.html (accessed on 23 January 2021).

46. ublox. ZOE-M8B-Ultra-Small, Super Low-Power U-Blox M8 GNSS SiP Module. Data Sheet; UBX-17035164; U-Blox: Thalwil, Switzerland, 2020; Available online: https:/ / www.u-blox.com/sites/default/files/ZOE-M8B_DataSheet_\%28UBX-17035164\%29. pdf (accessed on 23 January 2021).

47. LP3996 Dual Linear Regulator with $300 \mathrm{~mA}$ and $150 \mathrm{~mA}$ Outputs and Power-on-Reset. Available online: https:/ / www.ti.com/ lit/ds/snvs360d/snvs360d.pdf?ts=1612959466078\&ref_url=https\%253A\%252F\%252Fwww.google.com\%252F (accessed on 10 November 2020).

48. Semtech. SX1272/3/6/7/8: LoRa Modem Design Guide; Semtech Corporation: Camarillo, CA, USA, 2013; Available online: https://usermanual.wiki/Pdf/LoraDesignGuideSTD.1867307571/html (accessed on 23 January 2021).

49. Merlone, A.; Lopardo, G.; Sanna, F.; Bell, S.; Benyon, R.; Bergerud, R.A.; Bertiglia, F.; Bojkovski, J.; Böse, N.; Brunet, M.; et al. The MeteoMet Project-Metrology for Meteorology: Challenges and Results: The MeteoMet Project-Metrology for Meteorology. Meteorol. Appl. 2015, 22, 820-829. [CrossRef]

50. Vaisala. Vaisala Radiosonde RS41-SG; Vaisala: Vantaa, Finland, 2017; Available online: https:/ / www.vaisala.com/sites/default/ files/documents /WEA-MET-RS41-Datasheet-B211321EN.pdf (accessed on 23 January 2021).

51. Madgwick, S.O.H.; Harrison, A.J.L.; Vaidyanathan, R. Estimation of IMU and MARG Orientation Using a Gradient Descent Algorithm. In Proceedings of the 2011 IEEE International Conference on Rehabilitation Robotics, Zürich, Switzerland, 29 June-1 July 2011; pp. 1-7.

52. Warhaft, Z. Laboratory Studies of Droplets in Turbulence: Towards Understanding the Formation of Clouds. Fluid Dyn. Res. 2008, 41, 011201. [CrossRef]

53. Siebert, H.; Shaw, R.A.; Warhaft, Z. Statistics of Small-Scale Velocity Fluctuations and Internal Intermittency in Marine Stratocumulus Clouds. J. Atmos. Sci. 2010, 67, 262-273. [CrossRef]

54. Katul, G.G.; Geron, C.D.; Hsieh, C.-I.; Vidakovic, B.; Guenther, A.B. Active Turbulence and Scalar Transport near the ForestAtmosphere Interface. J. Appl. Meteorol. Climatol. 1998, 37, 1533-1546. [CrossRef]

55. Radkevich, A.; Lovejoy, S.; Strawbridge, K.B.; Schertzer, D.; Lilley, M. Scaling Turbulent Atmospheric Stratification. III: Space-Time Stratification of Passive Scalars from Lidar Data. Q. J. R. Meteorol. Soc. 2008, 134, 317-335. [CrossRef]

56. Golshan, M.; Abdunabiev, S.; Tomatis, M.; Fraternale, F.; Vanni, M.; Tordella, D. Intermittency Acceleration of Water Droplet Population Dynamics inside the Interfacial Layer between Cloudy and Clear Air Environments. arXiv 2020, arXiv:2007.06497v3. 